Distribution Category:

Cogeneration Research

(UC-317)

ANL-89/23

ARGONNE NATIONAL LABORATORY

9700 South Cass Avenue

Argonne, Illinois 60439
ANL $--89 / 23$

DE9 $0 \quad 008093$

\title{
EVALUATION OF INDUSTRIAL
}

MAGNETIC HEAT PUMP/REFRIGERATOR CONCEPTS

THAT UTILIZE SUPERCONDUCTING MAGNETS

by

J. A. Waynert, A. J. DeGregoria, R. W. Foster, and J. A. Barclay

\author{
ASTRONAUTICS CORPORATION OF AMERICA \\ Astronautics Technology Center \\ 5800 Cottage Grove Road \\ Madison, Wisconsin 53716
}

June 1989

Prepared for Argonne National Laboratory

under Subcontract No. 90232402

ANL Project Manager

Kenneth L. Uherka

Materials and Components Technology Division

Work Sponsored by

U. S. DEPARTMENT OF ENERGY

Assistant Secretary for Conservation and Renewable Energy

Office of Industrial Programs 


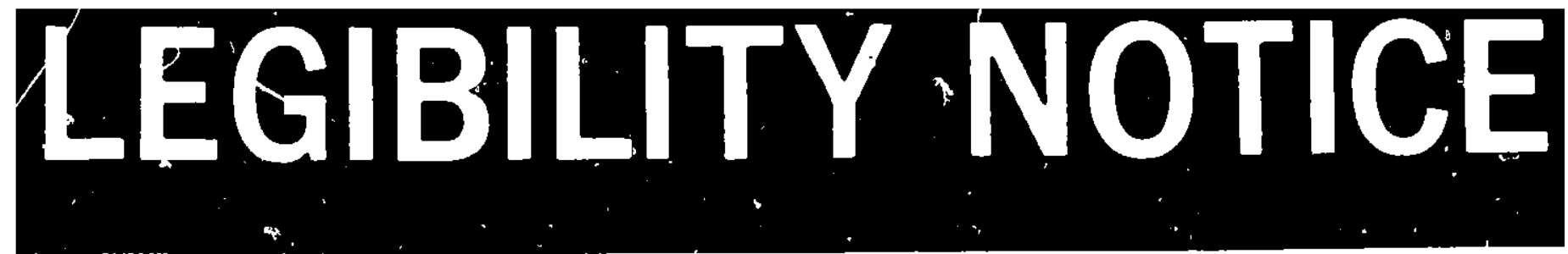

\section{A major purpose of the Techni-} cal Information Center is to provide the broadest dissemination possible of information contained in DOE's Research and Development Reports to business, industry, the academic community, and federal, state and local governments.

Although a small portion of this report is not reproducible, it is being made available to expedite the availability of information on the research discussed herein. 
ABSTRACT VII

EXECUTIVE SUMMARY 1

$\begin{array}{ll}\text { 1. INTRODUCTION } & \mathbf{5}\end{array}$

2. BACKGROUND $\quad 6$

2.1 Principles of Magnetic Heat Pumps $\quad 6$

2.2 History of Magnetic Heat Pumps 10

3. LIQUID HYDROGEN MARKET AND POTENTIAL IMPACT OF A $\begin{array}{ll}\text { MAGNETTC LIQUEFIER } & 12\end{array}$

$\begin{array}{ll}3.1 & \text { Overview of the Hydrogen Market } \\ 3.2 & 12\end{array}$

3.2 The Liquid Hydrogen Market - Production and Demand 13

$\begin{array}{lll}3.3 & \text { Cost of Liquid Hydrogen } & 13\end{array}$

$\begin{array}{lll}\text { 3.3.1 Distribution } & 15\end{array}$

$\begin{array}{lll}3.3 .2 & \text { Feedstock } & 17\end{array}$

$\begin{array}{lll}3.3 .3 & \text { Liquefaction } & 18\end{array}$

4. LIGUEFACTION OF HYDROGEN 21

$\begin{array}{lll}4.1 & \text { Gas-Cycle Liquefiers } & 21\end{array}$

4.2 Magnetic-Cycle Liquefters 23

4.2.1 Magnetic Refrigerator Design Options 24

4.2.1.1 Refrigeration Cycle 24

4.2.1.1.1 Carnot Cycle 24

4.2.1.1.2 Brayton Cycle 25

4.2.1.1.3 Ericsson and Stirling Cycles 25

4.2.1.2 Magnetic Materials $\quad 25$

4.2.1.3 Heat Exchange $\quad 27$

4.2.1.4 Magnetization/Demagnetization $\quad 28$

4.2.1.5 Magnet Configuration 31

4.2.1.6 Heat Sink 32

4.2.1.7 Source/Sink Connection $\quad 32$

4.2.2 Active Magnetic Regenerative (AMR) Liquefier 33

4.2.3 Description of the AMR Mociel 36

4.2.4 AMR Performance Analysis 38

4.2.5 Scaling and Cost of AMR Liquefier $\quad 49$

5. UPDATE OF ROOM -TEMPERATURE MHP REPORT 53

6. MAGNETIC REFRIGERATOR APPLICATIONS UP TO $300 \mathrm{~K}$

$\begin{array}{ll}\text { 7. SUMMARY/CONCLUSIONS } & 57\end{array}$

8. RECOMMENINATIONS 59

$\begin{array}{lll}9 . & \text { REFERENCES } & 61\end{array}$ 


\section{LIST OF FIGURES}

Figure

Number

Pater

NanulX.J

$\begin{array}{lll}\text { la } & \text { A simple magnetic refrigerator. } & 8\end{array}$

lb Temperature-entropy cycle followed by the magnetic material undergoing a Carnot cycle.

2a Schematic of a regenerative magnetic refrigerator for near room temperature operation.

$2 \mathrm{~b} \quad$ Temperature-entropy cycle with regeneration showing the heat flows which must be accomplished during each cycle.

3 The present industrial LH2 production system.

4 The relationship of the form of delivered hydrogen to customer annual demand.

5 Capital investment distribution in present liquefaction plants as proportioned to the work distribution over the refrigeration and liquefaction temperature range.

6 Typical gas cycle hydrogen ilquefier.

7 Magnetic entropy-temperature diagrams tllustrating several thermodynamic cycles with ferromagnetic materials.

8 Entropy-temperature diagram for typical ferromagnet that llustrates the relative magnitudes of heat flow in different parts of the cycle.

9 Schematic of the basic components of the AMR.

10 The temperature profiles that result from shuttling gas from left to right after magnetization and right to left after demagnetization.

11 MR using an active magnetic regenerative wheel.

12a AMR 20 to $77 \mathrm{~K}$ refrigerator performance showing average cooling power versus mass flow rate for several values of particle size.

12b AMR 20 to $77 \mathrm{~K}$ refrigerator performance showing COP efficiency versus mass flow rate for several values of particle stze.

12c AMR 20 to $77 \mathrm{~K}$ refrigerator performance showing pressure drop versus mass flow rate for several values of particle size.

13 Schematic of a multi-stage AMR hydrogen liquefier. 


\section{LIST OF FIGURES (Cont'd.)}

Figure

Page

Number

Number

14 Effects of the number of stages of the 20 to $77 \mathrm{~K} \mathrm{AMR}$ hydrogen

45

liquefier on performance.

15 Overall efficiency of the 20 to $300 \mathrm{~K}$ hydrogen liquefier as a

function of the efficiency of the 20 to $80 \mathrm{~K}$ magnetic liquefier.

16 Effect of AMR period on performance.

48

17 Effect of the field change on performance, expressed in terms of the adiabatic temperature change of the ideal magnetic material at $80 \mathrm{~K}$

18 Mean wheel diameter versus liquefaction rate of magnetic

52

19 Complete liquefier system cost as a function of liquefaction rate.

52 


\section{LIST OF TABLES}

Table

Page

Number

Number

I Growth History and Projected Demand for "Small User" Liquid Hydrogen Market

II Hydrogen Feedstock Sources and Relative Costs $\quad 17$

III Relative Prices by Volume frr Merchant Hydrogen 18

IV Operating Costs of an $850 \mathrm{t} / \mathrm{d}$ Hydrogen Liquefaction System 19

$\begin{array}{lll}\text { V } & \text { Criteria for Selection of Magnetic Materials } & 27\end{array}$

VI Cost Breakdown of $1 \mathrm{t} / \mathrm{d}$ Hydrogen Magnetic Liquefier 51

VII Characteristics of a $533 \mathrm{l} / \mathrm{h}(1 \mathrm{t} / \mathrm{d})$ Magnetic Hydrogen 53 Liquefier

VIII Cost Breakdown of a $50 \mathrm{~kW}$ Supermarket Freezer $\quad 56$

IX AMR Performance Specifications for $300 \mathrm{~K}$ to $80 \mathrm{~K}$ Operation $\quad 57$

X Efficiency Comparison of 1 Ton Per Day All-Gas Hydrogen 60

Liquefiers to Magnetic Liquefier Combinations 


\title{
EVALUATION OF INDUSTRIAL MAGNETIC HEAT PUMP/REFRIG_RATOR CONCEPTS THAT UTLIZE SUPERCONDUCTING MAGNETS
}

by

\author{
J. A. Waynert, A. J. DeGregoria, R. W. Foster, and J. A. Barclay
}

\begin{abstract}
This report provides a preliminary assessment of some magnetic heat pump (MHP)/refrigeration concepts for cryogen liquefaction and other industrial applications. The study was performed by Astronautics Corporation of America for Argonne National Laboratory under the sponsorship of the U.S. Department of Energy. Applications of interest range from the liquefaction of gases $(20 \mathrm{~K}$ to $100 \mathrm{~K}$ ) to cold storage refrigeration for food preservation ( $250 \mathrm{~K}$ to $320 \mathrm{~K}$ ) to heat pumps utilizing industrial waste heat ( $350 \mathrm{~K}$ to $400 \mathrm{~K})$. Initial market penetration of magnetic refrigeration devices is anticipated for lowtenperature industrial applications such as the cryogen liquefaction field, and the major focus of the study is on hydrogen liquefaction $(20 \mathrm{~K})$ utilizing a liquid nitrogen heat sink $(77 \mathrm{~K})$. A brief market analysis indicated that there is a need for small ( $\sim 1$ ton/day liquid hydrogen) hydrogen liquefiers with dispersed usage at appropriate sites in the country to reduce distribution costs. This provides an Ideal market niche for magnetic liquefiers since conventional gas-cycle liquefiers cannot be economically scaled to small sizes. A number of design options for hydrogen liquefiers are analyzed, including thermodynamic cycles; magnetic materials; heat exchangers; process of magnetization / demagnetzation; magnet configurations; source/sink connections; and regenerative, recuperative, and active magnetic regenerative concepts. A threestage rotary version of an active magnetic regenerative refrigerator concept, incorporating solenoldal superconducting magnets ( 8 tesla), was selected for more cietalled modeling. A parametric analysis was performed to determine the sensitivity of critical design variables on liquefier performance and costs. The size scaling and cost analyses indicate that, relative to a comparable gas-cycle liquefier, a one ton/day magnetic hydrogen liquefier is much more compact, has a polentially higher system efficiency, and has lower capital/operating costs.
\end{abstract}




\section{EXECUTIVE SUMMARY}

This report presents the results of a study funded by the Argonne National Laboratory (ANL) for the Office of Industrial Programs (OIP). A subcontract was issued to Astronautics Corporation of America by ANL. DOE/OIP/ANL's primary interest in magnetic heat pumps (MHPs) is a result of the potential industrial energy savings that may be achieved through the use of the highly efficient devices. Further, the discovery of high-temperature superconductors and the desire for alternate energy conversion devices that do not use chlorofluorocarbons renewed DOE's interest in MHP technology. MHPs are applicable for all temperature ranges, from liquefaction of gases to cold storage of foods to industrial heat recovery. With respect to potential energy savings, refrigerator and heat pump applications near room temperature clearly are where MHPs should be applied. However, following the workshop held in October 1988 (see page 11) to compare MHPs to vapor compression devices for near-room-temperature heating and cooling applications, the general conclusion was that while MHPs could compete on a performance basis, they were presently too costly to replace existing vapor-compression devices. However, it was suggested that there is a clear need for more efficient refrigerators in the cryogen liquefaction field, and especially for liquid hydrogen. Thus, until high-temperature superconductors operating at $77 \mathrm{~K}$ or above are commercially viable, the most appropriate initial industrial market for MHPs is probably in the lowtemperature gas liquefaction sector. In particular, the liquid hydrogen market, with its $20 \mathrm{~K}$ temperature of liquefaction and projected growth rate, appears to offer an ideal market nithe for magnetic liquefiers. This top-level study assesses whether magnetic liquefiers for hydrogen are potentially superior to conventional liquefiers on a cost performance basis.

A brief analysis of the liquid hydrogen market indicates that there are presently six large (typically tens of tons per day, per unit) centralized hydrogen liquefiers in the United States. From these centralized production centers, liquid hydrogen $\left(\mathrm{LH}_{2}\right)$ is distributed to perhaps 12 storage terminals whose locations have been established according to product demand. Here, $\mathrm{LH}_{2}$ is stored in very large cryogenic tanks. From the terminals, $\mathrm{LH}_{2}$ is trucked to distribution terminals which also nandle other gaseous products. There are perhaps five times as many distribution terminals as storage terminals. Finaliy, the product is trucked to the customer. At present, the delivered price of hydrogen can vary by a factor of ten depending on the quantity used, the distance trucked, and the form, gaseous or liquid, in which the hydrogen is transported. The transportation distance can have a major impact on the price to the customer, especially the small user. As an example, the customer price can be reduced by about $18 \%$ if the transportation distance can be decreased from 1500 miles to under 200 miles. Thus, it appears that the hydrogen market could be expanded through easier 
availability and decreased costs if the distribution system could be economically decentralized through a dispersed usage of smaller, less costly liquefiers.

Conventional gas cycle liquefiers cannot be economically scaled to the $1 \mathrm{t} / \mathrm{d}$ size. A $5 \mathrm{t} / \mathrm{d}$ unit costs about $\$ 12.5$ million and operates at about $25 \%$ efficiency. (Efficiency is used here as the ratio of the minimum work of liquefaction to the actual work). It is not likely that the efficiency of conventional units can be maintained as the units are scaled down to the $1 \mathrm{t} / \mathrm{d}$ size. It is not unreasonable to assume the efficiency of a conventional $1 \mathrm{t} / \mathrm{d}$ gas cycle liquefier to be $15-20 \%$ of ideal. At best, the capital cost would be $\$ 2.5$ million. These are the numbers, i.e., an efficiency of about $20 \%$ and capital cost of at least $\$ 2.5$ million, to which a $1 \mathrm{v} / \mathrm{d}$ MHP must be compared.

This study emphasizes an MHP operating between $18 \mathrm{~K}$ and $86 \mathrm{~K}$, nominally $20 \mathrm{~K}$ to $77 \mathrm{~K}$ with allowance for heat exchange at the cold and hot sinks. It is assumed that liquid nitrogen ( $\left.\mathrm{LN}_{2}\right)$ is available to precool the hydrogen gas, near atmospheric pressure, to $77 \mathrm{~K}$. The magnetic liquefier cools and liquefies the precooled hydrogen gas and exhausts heat to the $\mathrm{LN}_{2}$. To achieve reasonable efficiency of liquefaction, the MHP must incorporate several intermediate temperature stages to remove the sensible heat and the exothermic energy of the ortho- to para-hydrogen conversion. A good compromise between efficiency and system complexity is achieved by three stages with nominal cold temperature operating points of $60 \mathrm{~K}, 40 \mathrm{~K}$, and $20 \mathrm{~K}$.

A series of design options for both major components and the entire system of the MHP were analyzed, including thermodynamic cycles; magnetic materials; heat exchangers; process of magnetization/demagnetization; magnet configurations; source/sink connections; and regenerative, recuperative, and active magnetic regenerative concepts. The concept that was selected for more deiailed modeling was a rotary version of an active magnetic regenerative refrigerator (AMR). A rotary version of the AMR was chosen because it naturally produces continuous cooling, can be designed with more uniform structural loads, and appears relatively easy to implement. In the rotary design, a series of parallel-flow, packed-particle beds of magnetic material are assembled into the form of a ring or wheel. The wheel is actually composed of three parnllel disks with a common axis of rotation. Each disk is a stage of the AMR. The magnetic field is proviled by a series of solenoidal magnets which enclose roughly one-third of the wheel circum.erence. There are manifolds with sliding seals to the beds to allow the appropriate gas flow during heat exchange with the bed material. In this design, helium gas at $1 \mathrm{MPa}(10 \mathrm{~atm}$.) is circulated to communicate between the hot and cold sinks and the particle bed. The hydrogen gas is cooled by counterflow heat exchange with the helium gas. 
A parametric performance analysis of the AMR was done considering the effect on the efficiency of particle size of the bed material, mass flow rate of the helium gas, magnetic field strength, and frequency of the cycle operation. To perform this analysis, the thermomagnetic properties of the magnetic material are required. A candidate magretic material is $\operatorname{Er}_{x} \mathrm{Gd}_{(1-x)} \mathrm{Al}_{2}$ but to simplify the analysis, ideal magnetic properties were used. Reasonably high efficiency and low pressure drop across the bed occur for $0.01-\mathrm{cm}$-diameter particles packed in a bed $5 \mathrm{~cm}$ long at $50 \%$ porosity for an $8 \mathrm{~T}$ field change with a helium mass flow rate of $0.5 \mathrm{~g} / \mathrm{s}$ for each square centimeter of bed cross-section.

Some interesting results were found in a comparison between the magnetic and all-gas cycle liquefiers. A $1 \mathrm{t} / \mathrm{d}(530 \mathrm{l} / \mathrm{h})$ magnetic liquefier is very compact; the mean wheel diameter is $145 \mathrm{~cm}$. A comparabic gas cycle liquefier is projected to occupy roughly $5 \mathrm{~m} \times 10 \mathrm{~m}$. The capital cost of the magnetic liquefier is estimated at $\$ 1.07$ million versus $\$ 2.5$ million for the gas cycle device. The overall efficiency of the hybrid $\mathrm{LN}_{2}$ /magnetic device is $24 \%$ versus $20 \%$ (projected) for the gas cycle device. The efficiency difici ence represents a $17 \%$ reduction in electrical power requirements. In terms of U.S. energy usage, the rutential amount of energy saved is very small. On the other hand, the expected hydrogen market expansion should mean many new ventures producing more jobs. In addition, the use of magnetic refrigeration to liquefy hydrogen is an ideal opportunity to introduce a new energy-conserving technology which promises to have a much broader range of future applications, particularly near room temperature.

Based on the results of the analysis described herein, it seems natural to pursue further development of a magnetic liquefier. We recommend that DOE consider nore research and development in this area commensurate with their overall objectives. 


\section{INTRODUCTION}

The Office of Industrial Programs in the U.S. Department of Energy (DOE) and Argonne National Laboratory (ANL) are active in the development of magnetic heat pumps (MHPs) for industrial refrigeration applications. Conventional refrigeration technology utilizes gas refrigerants in a vapor-compression cycle for applications near room temperature and in reverse-Brayton or other cycles for applications at cryogenic temperature. The conventional technology is well understood, well established, and mature to the point that there is limited scope for improvement without major investments.

DOF and ANL recognize that MHPs, with their solid working material, are compact and offer high efficiency and potentially high reliability at competitive costs. The performance advantages are especially pronounced in the temperature range below $80 \mathrm{~K}$ and especially in smaller-scale devices. One particular industrial application which appears promising for initial market penetration is in a relatively small scale (less than 5 ton per day) MHP unit for hydrogen liquefaction.

This report summarizes the results of an Astronautics Corporation of America (ACA) contract study for ANL to evaluate magnetic heat pumps with the major application emphasis on the liquefaction of hydrogen. The objectives of the study are to:

- Establish operating limits and performance characieristics of MHPs for liquefying hydrogen, considering;

* rotating vs. reciprocating devices,

* alternative magnet configurations,

* alternative thermodynamic cycles,

* alternative magnetic materials,

* active magnetic regenerative vs. recuperative/regenerative cycles,

* efficiency, cooling power, and power density, and

* parametric sensitivity studies of magnetic materlal, cooling capacity, and field strength;

- Provide a brief assessment of scaling to other low-temperature applications with differing heat source/sink conditions; 
- Expand and update the previous contract study (Contract No. 81032401) for A.NL on "Impact of High Temperature Superconductors on Room Temperature Magnetic Heilt Pumps/Refrigerators"; and

- Prepare a final report which considers the impact of commercialization of the device and gives recommendations for future research and development.

The report first presents the principles and history of MHPs in Section 2. Then the present hydrogen market and the potential market niche for MHPs are discussed in Section 3. Section 4 provides some background on conventional gas-cycle devices for hydrogen liquefaction and then introduces potential magnetic cycle devices. Section 5 updates previous relared MHP studies, while Section 6 considers other applications up to room temperature. Finally, recommendations for future work are given in Section 7.

\section{BACKGROUND}

\subsection{Principles of Magnetic Heat Pumps}

Heat pumps are similar to refrigerators in that both remove heat from a cold source and transfer energy to a warm sink under the application of work. Heat pumps and refrigerators differ in that heat pumps emphasize the heat rejected (as in a space heate-) while refrigerators emphasize the heat absorbec (as in a freezer). It is common, though, to consider heat pumps as a more generai category which includes refrigerators. That is the approach used throughout this paper, and heat pump and refrigerator are thus used interchangeabiy.

Contrary to gas-cycle heat pumps which rely on the expansion and compression of a gas to achieve the energy transfer from coid to warm sinks, magnetic heat pumps (MHPs) rely on the magnetocaloric effect. The magnetocaloric effeci refers to the reversible change in temperature exhibited by certain magnetic materials as they experience increasing or decreasing magnetic fields. Under cerain temperature conditions, paramagnetic and ferromagnetic materials warm up upon ajiabatic application of a magnetic field or expel heat at constant temperature if heat transfer is performed during field application. The process is highly reversible so that adiabatic removal of the field will cool the material. Conversely, if the temperature is constant during the field reduction, heat must be absorbed.

The materials commonly used in MHPs are rare earth compounds. For example, gadolinium gallium garnet(1) is a paramagnetic material used in MHPs operating in the $1.8 \mathrm{~K}$ to $20 \mathrm{~K}$ temperature range. As the operating temperature is raised, the lattice specific heat increases rapidly. 
The lattice cortribution to the thermal mass of the magnetic material reduces the adiabatic temperature change with applied field; i.e., the thermal energy begins to exceed the magnetic energy in a paramagnetic system. Therefore, for operating temperatures above about $20 \mathrm{~K}$, ferromagnetic materials --with their exchange enhancement of the applied field near their Curie temperature (magnetic transition temperature)-- are required.(2) A prospective material series for the hydrogen liquefier is $\mathrm{Er}_{\mathbf{x}} \mathrm{Gd}_{(1-\mathrm{x})} \mathrm{Al}_{2 .(3)}$ Its magnetic transition temperature can be adjusted from $165 \mathrm{~K}$ to 13 $\mathrm{K}$ as $\mathrm{x}$ is varied from zero to one.

The magnetocaloric effect can be utilized to produce refrigeration. Figure la shows a schematic of a magnetic refrigerator whose operation is explained below. Assume for the simplest ideal Carnot cycle, as shown in Fig. 1b, that the working magnetic material (WM) is at the heat reservoir (HR) temperature. The upper thermal switch is closed while the lower is kept open. As the magnetic field is increased, energy transfers to the HR, because the WM is hotter than the HK. At the maximum field, the heat transfer ceases; the WM is isolated from the HR by opening the switch, and the field is then decreased. The temperature of the WM decreases with the field until its temperature is roughly equal to that of the heat source (HS). At that point, the lower thermal switch is closed and heat transfers from the HS to the WM as the field is reduced to zero. The WM is again isolated by opening the lower switch. Heat transfer is discontinued, and the field is increased until the WM temperature equals or slightly exceeds that of the HR to repeat the cycle. This cycle, assuming two adiabatic steps and perfect heat transfer in the isothermal steps, is shown in Fig. Ib on a typical low-temperature-entropy $(T-S)$ diagram.

The adiabatic temperature change in a magnetic Carnot cycle is generally small, perhaps 1-2 $\mathrm{K}$ per Tesla. For a temperature span larger than about $10 \mathrm{~K}$, other magnetic cycles such as Brayton or Ericsson are typically used (rather than a series of Carnot cycles). In these cycles, the temperature span is increased by the use of an external thermal device called a regenerator or recuperator. The regenerator or recuperator acts as a thermal flywheel, absorbing heat in one part of the cycle in high ruagnetic fields and or rejecting heat to the magnetic material in the low-field part of the cycle, as its temperature ranges between $T_{C}$ and $T_{H}$, respectively. Figures $2 \mathrm{a}$ and $\mathrm{b}$ illustrate a Brayton cycle with regeneration (shown both schematically and on a representative $T$-S diagram) for a ferromagnetic material. In Fig. 2a, a schematic of a regenerative magnetic refrigerator is shown. Figure $2 b$ shows a regenerative cycle superposed on the $T-S$ diagram for a typical ferromagnetic material. Note that the heat flow in the regereration step of the cycle (shaded area in Fig. 2b) is much larger than in the similar area under the CHEX stage of the cycle. As the temperature span between $T_{C}$ and $T_{H}$ increases, the ratio of $Q_{R e g} / Q_{C}$ becomes larger. A further discussion of regeneration is given in section 4.2.1.3. 


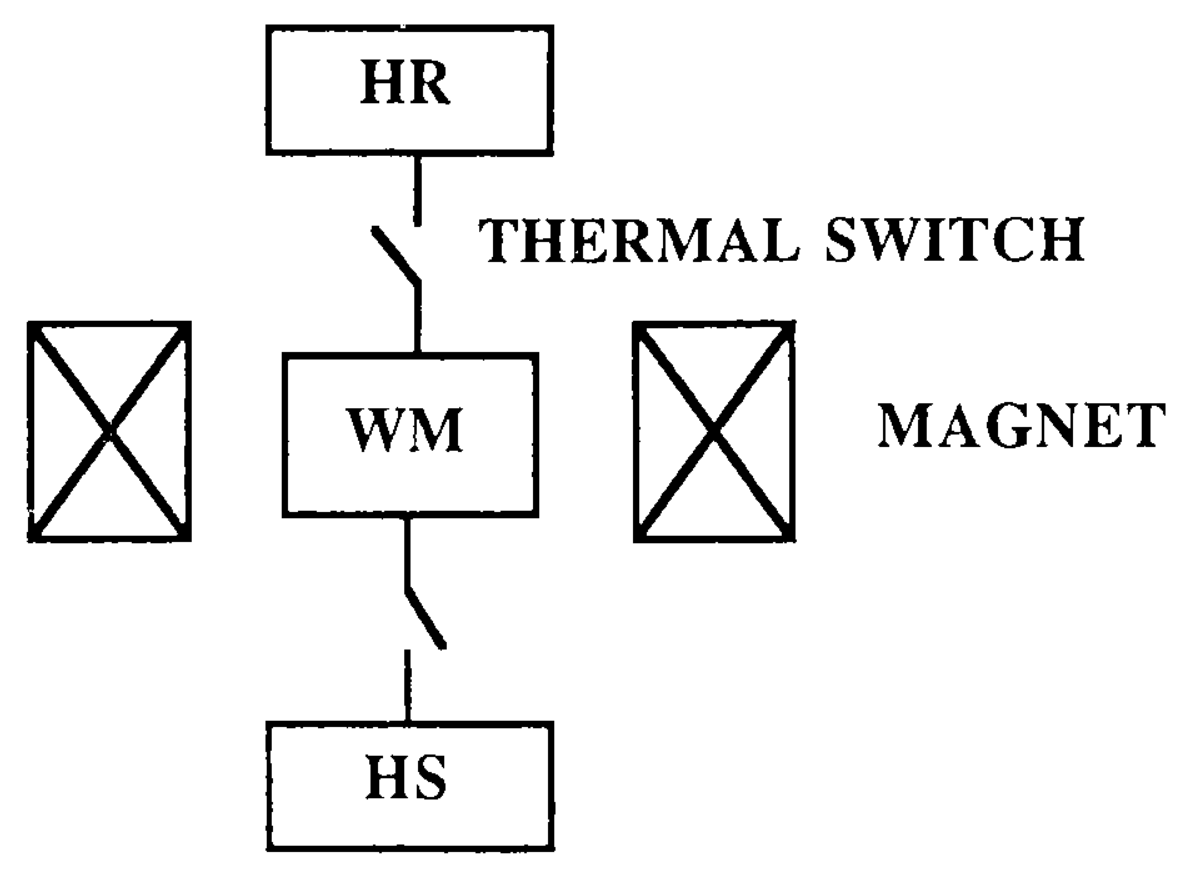

Fig. 1a. A simple magnetic refrigerator.
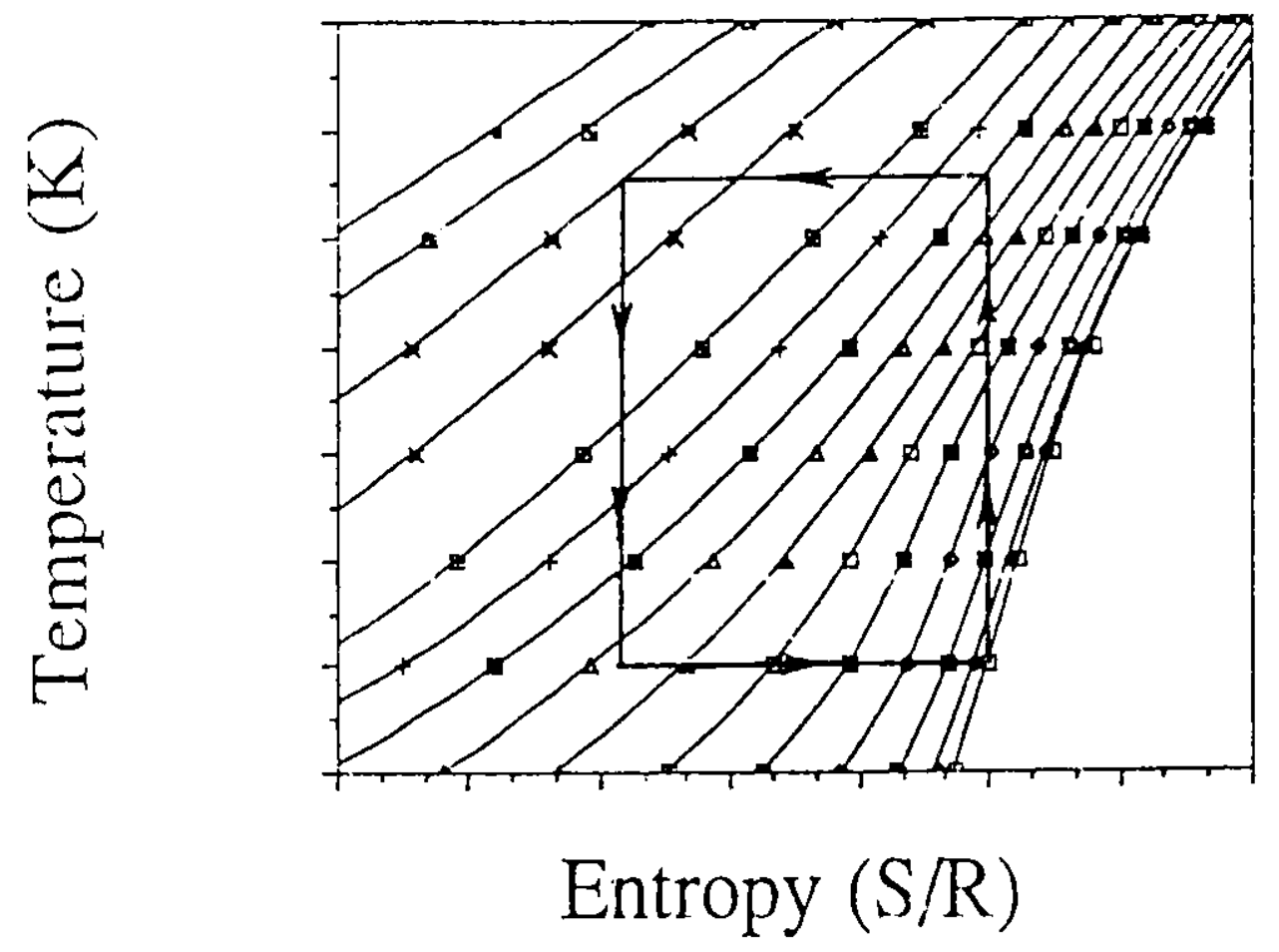

Fieid Strength (?)

๑ 0.0

- 0.5

- $\quad 1.0$

- 1.5

- 2.0

อ 25

- 3.0

ه 3.5

- 40

$+\quad 4.5$

田 5.0

$\times \quad 6.0$

$\times \quad 7.0$

- 8.0

- 9.0

Fig. Ib. Temperature--entropy cycle followed by the magnetic material ur.dergoing a Carnot cycle. 


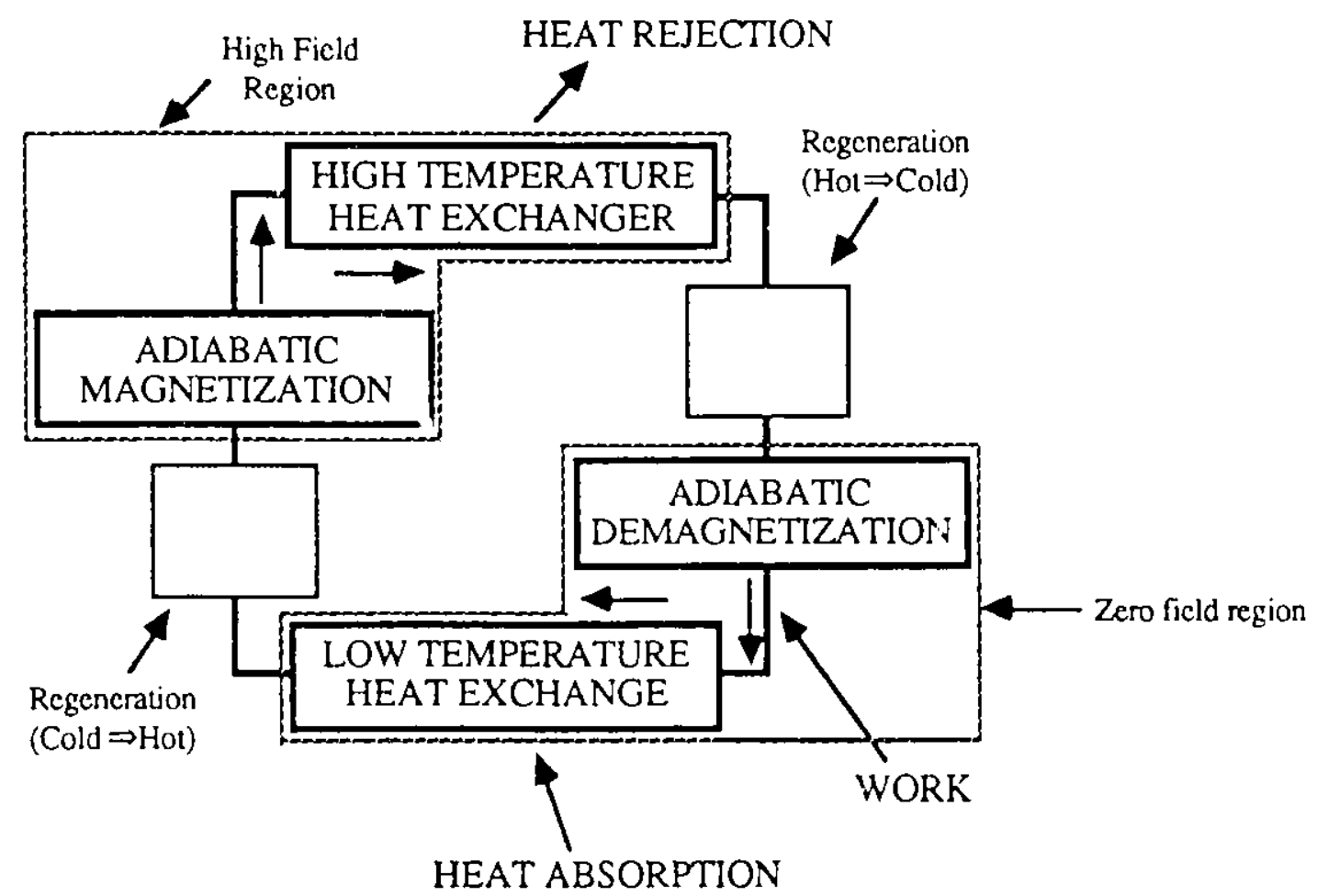

Fig. 2a. Schematic of a regenerative magnetic refrigerator for near room temperature operation.

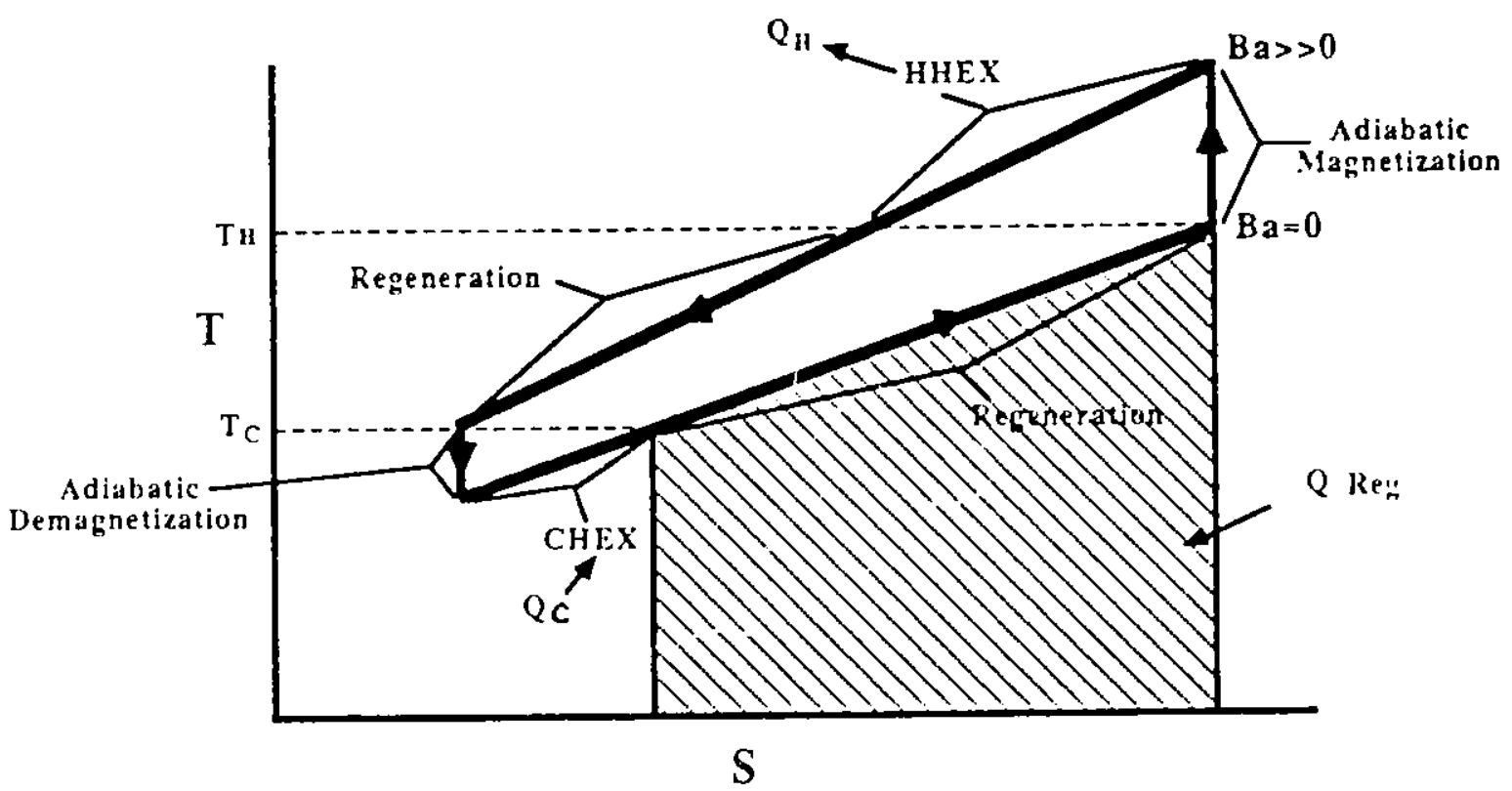

Fig. 2b. Temperature--entropy cycle with regeneration showing the heat flows which must be accomplished during each cycle. 
The terms regeneration and recuperation are not uniquely defined in the refrigeration community. In this report, regenerative heat exchange refers to thermal energy exchange in which the temperature distribution is time-dependent, i.e., periodic. An example is a packed-particle bed of lead shot in which warm gas flows in one direction, depositing heat into the bed, followed by heat recovery as cold gas flows through the bed in the opposite direction. Thus, the temperature distribution in the bed varies with time. In contrast, a recuperative heat exchanger has a temperature distribution which is time-independent. A temperature gradient exists in the device, but the temperature at each point does not vary in time. A common example is the counter-flow heat exchanger.

Magnetic refrigeration cffers a third and unique possibility for the thermal flywheel of which there is no counterpart in gas-cycle devices. It is possible to use the working magnetic material as the regenerator. This regenerator is referred to as an active magnetic regenerator or $A M R$ and refrigerators based on this regenerator are also referred to as AMRs. The AMR is the focal point of this study. The MHP hydrogen liquefaction concept considered in this study operates between about $18 \mathrm{~K}$ and $86 \mathrm{~K}$ and thus, requires regeneration. Because the heat absorbed/rejected by the regenerator is several times larger than the heat absorbed from the source in a single cycle, it is evident that excellent heat transfer during regeneration is required to obtain high efficiency. Also, higher fields yield greater cooling power with minimal increase in losses. This means higher efficiencies result from higher magnetic fields; thus, the need for superconducting magnets.

In addition to factors concerning the magnetic material, superconducting magnets, and excellent heat transfer to and from the magnetic material, there are other important considerations in the design of MHPs. Forces within the magnets, between magnets, and between the magnets and magnetic material can be large. Thus, an effective supporting structure is required to react to these forces. Some type of drive mechanism is needed to change the relative position of the magnetic material and the magnets to achieve the magnetization and demagnetization. Dewars and external heat exchangers are also required. Various sensors are needed to provide power, monitor temperatures and flow rates, and control the MHP.

\subsection{History of Magnetic Heat Pumps}

The discovery of the magnetocaloric effect (MCE) occurted in 1918 when A. Piccard and P.

Weiss(4) experimentally separated irreversible hysteretic heating from reversible heating and cooling upon magnetic field cycling. The metallic ferromagnet $\mathrm{Ni}$ was used in their experiments near its Curie temperature of $358^{\circ} \mathrm{C}(631 \mathrm{~K})$. In 1934 the effect was demonstrated in Fe metal(5) at over 
$1000 \mathrm{~K}$. Closer to room temperature, the effect in Gd metal ( $292 \mathrm{~K})$ has only relatively recently been measured.(6)

An early examination of the use of the MCE of ferromagnets in heat pumps was presented in 1948 when Iskendrian and Brillouin(7) described the magnetic thermodynamics of a useful cycle. Following this analysis, thermomagnetic heat engines using ferromagnetic working materials in the form of direct thermal to electrical energy converters were proposed.(8) The efficiencies of the Camot cycle convertors were low and the devices were not cost-competitive with other heat engines. More recently, regenerative-cycle (Ericsson) thermomagnetic generators have been proposed which offer much higher efficiencies. $(9,10)$ No major development programs presently exist on these promising devices.

After the discovery of ferrofluids, i.e., stable colloidal suspensions of ferromagnetic particles in carrier fluids, in 1965(11), there was a burst of activity on the use of ferrofluids as working materials in heat engines.(12-13) Although it is not clear from most of the published analyses of the thermodynamic cycles in the use of ferrofluids in MHPs, the MCE is the basis of operation in these units. Devices were actually demonstrated but the concentration of ferromagnetic particles $\left(\mathrm{Fe}_{2} \mathrm{O}_{3}\right)$ in ferrofluids could not be increased enough to make them viable. Operation well below the Curie temperature and the thermal addenda from the carrier fluid made the effective adiabatic temperature change of the $\mathrm{Fe}_{2} \mathrm{O}_{3}$ particles about $0.1 \mathrm{~K}$. Concentrated suspensions of gadolinium particles in mercury were investigated for near-room-temperature devices but the suspensions were not stable in applied fields.(14)

The first proposed use of the MCE of solid ferromagnets in magnetic heat pumps near room temperature was made by Brown(15) in the early 1970's when the "energy crisis" made high efficiency in thermal devices a strong technology driver. A reciprocating design using Gd metal, a $7 \mathrm{~T}$ magnetic field, and an alcohol-water mixture as the liquid regenerator was successfully operated in 1976.(16) This device ultimately spanned about $800 \mathrm{C}$ around the Curie point of $\mathrm{Gd}(292 \mathrm{~K})$ with no external thermal load. This pioneering work formed the basis of research and development programs at several laboratories around the world.

In parallel with the characterization and eventual use of magnetocaloric effect in ferromagnets above about $20 \mathrm{~K}$, the use of the MCE in paramagnets at temperatures below $20 \mathrm{~K}$ was pursued. From 1926(17.18) until 1966(19), the technique was used exclusively for very' small cooling powers (microwatts) below $1 \mathrm{~K}$. From 1966 to present, significant effort has been put into 
developing larger-cooling-power (watts) Carnot-cycle devices operating in the $1 \mathrm{~K}$ to $20 \mathrm{~K}$ region.(20)

Most of the work on magnetic refrigerators has been for cryogenic applications $(20,21,22)$ but several laboratories such as Idaho National Engineering Laboratory and David Taylor Research and Development Center have worked on room-temperatures devices. Several proof-of-concept devices for near-room-temperature operation have been built.(23-26) None of these devices has demonstrated efficiencies and reliabilities that match original predictions but the results were encouraging enough to move toward engineering prototypes.

In the last three years, the discovery of high-temperature superconductors and the recognition of the seriousness of ozone depletion by chlorofluorocarbons have increased interest in magnetic heat pump technology.(27) The DOE Office of Industrial Programs sponsored a workshop in the fall of 1988 at Herndon, VA, to assess whether magnetic heat pumps at room temperature could effectively compete with vapor-compression-cycle devices (VCD).(28) As a result of this meeting it was concluded that although magnetic heat pumps may compete with VCDs on a performance basis, they could not presently compete on a cost basis. Alternatively, MHP's were suggested as potentially economically viable for lower-temperature applications such as hydrogen liquefiers. A better definition of the potential of MHPs as liquefiers in comparison to conventional gas-cycle devices is an objective of this report.

\section{LIQUID HYDROGEN MARKET AND POTENTIAL IMPACT OF A MAGNETIC LIQUEFIER}

\subsection{Overview of the Hydrogen Market}

The energy content of the presently consumed commercial hydrogen accounts for $0.9 \%$ of the total U.S. energy consumption. While commercial hydrogen usage is small in terms of national energy consumption, hydrogen is a critical feed stock in ammonia production, methanol production, and petroleum refining. These commercial uses form the "Large User Hydrogen" marketplace. Within the Large User Hydrogen marketplace, there is a segment comprising the "Small User" of hydrogen. This marketplace inciudes such uses as the synthesis of chemicals, metallurgical processing, electronic component manufacture, vegetable oil processing, and others. The small user hydrogen market is a growing market and is presently paying the highest prices for hydrogen. The history and projected demand for small user hydrogen through the year 2000 is illustrated in Table I.(29) Wiinin the small user hydrogen market, the growth history and future growth projections of the merchant hydrogen subsector share the same characteristics, i.e., a history of high growth rate and a projected future of high growth rate. (29) 
TABLE I.

GROWTH HISTORY AND PROJECTED DEMAND FOR "SMALL USER" LIQUID
HYDROGEN MARKET

(all values in billion $\mathrm{SCF} /$ year)

\begin{tabular}{|l|c|c|c|c|c|c|}
\hline Market Segment & 1977 & 1980 & 1985 & 1990 & 1995 & 2000 \\
\hline Chemical & 49.2 & 58.6 & 78.4 & 104.9 & 140.9 & 187.9 \\
\hline Métals & 10.0 & 11.1 & 13.2 & 15.3 & 18.6 & 22.1 \\
\hline Fats and Oils & 8.1 & 8.7 & 9.6 & 10.0 & 10.6 & 11.0 \\
\hline Electronics & 2.1 & 2.4 & 3.1 & 4.0 & 5.1 & 6.5 \\
\hline Pharmaceuticals & 0.5 & 0.7 & 0.9 & 1.3 & 1.8 & 2.4 \\
\hline Float Glass & 0.9 & 1.0 & 1.2 & 1.4 & 1.8 & 2.1 \\
\hline TOTAL & 70.8 & 82.5 & 106.4 & 136.9 & 178.8 & 232.0 \\
\hline
\end{tabular}

\subsection{The Liquid Hydrogen Market - Production and Demand}

Figure 3 presents the geographic distribution of liquid hydrogen production in the United States today. The production capacity of this national system is approximately 143 tons per day (TPD). The commercial and industrial users account for the majer portion, $82 \%$, of the demand. The government uses an average of 14 tons per day, primarily for space transportation and missile propulsion. Thus the present production capacity exceeds the present demand by a factor of almost two. This surplus of production is projected to decrease in the future until production capacity equals demand around the year 2010. However, the projections of future liquid hydrogen use by both the military and NASA can have a significant impact on this condition. Projections of future use of liquid hydrogen in space applications call for a significant growth in the next decade. This growth will occur primarily in the southeastern and western market areas.

\subsection{Cost of Liquid Hydrogen}

The cost of $\mathrm{LH}_{2}$ to the small user depends on the details of the distribution system, the source of the feed stock, and the capital and operating costs associated with the method of liquefaction. The three are interrelated in that a smaller, cost-effective liquefier might result in a more decentralized distribution system which may also affect the solution of the most appropriate feed stock source. In the following sections, the distribution system, feed stock sources, and methods of liquefaction for the present $\mathrm{LH}_{2}$ market dre discussed. A qualitative assessment of the potential impact of a relatively small magnetic hydrogen liquefier can be addressed once the three 


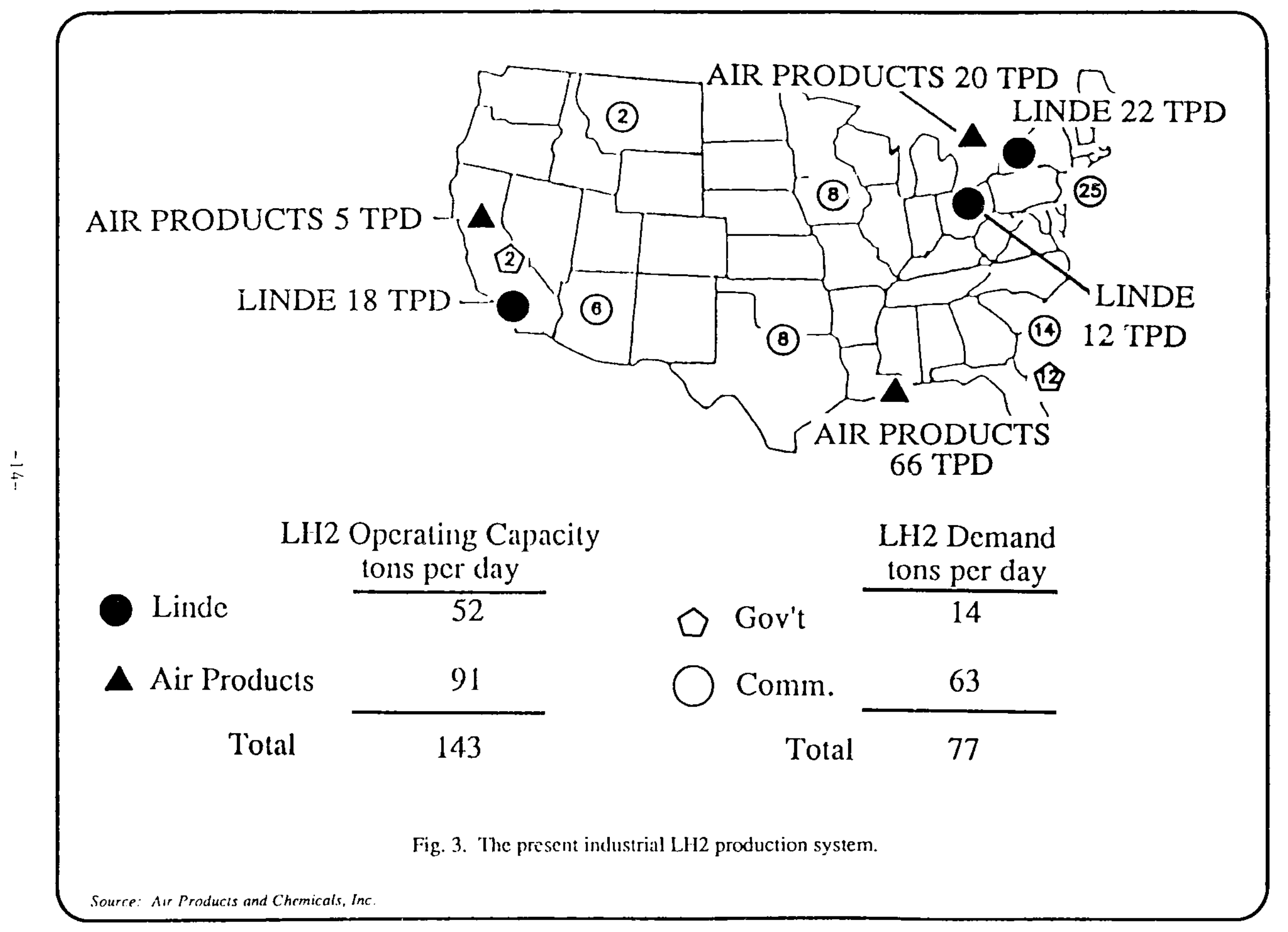


cost factors (distribution, feed stock, liquefier) are understood. A quantitative assessment of the impact is beyond the scope of this report.

\subsubsection{Distribution}

The present liquid hydrogen $\left(\mathrm{LH}_{2}\right)$ distribution system is based on the centralized location of production facilities. A liquid hydrogen product is shipped by truck from the large centralized production facilities to liquid hydrogen terminals, perhaps ten in number, which make up a second level of the distribution system. At these liquid hydrogen terminals, the bulk product is stored in large cryogenic tank systems. The liquid hydrogen product is then reshipped to supply a system of 20 to 30 distribution terminals which also sell other gas products. From the distribution terminals, the liquid hydrogen product is again moved by cryogenic tanker trucks to the customer locations. The local delivery costs significantly contribute to the delivery price of the hydrogen product. For example, there is an $18 \%$ reduction in the liquid hydrogen sales price if the hauling distance can be reduced from 1500 to 200 miles. (30) Clearly, the cost of shipment from the centralized production facility to the hydrogen terminals to the distribution points and finally to the customer represent a significant portion of the final ieli 'ered product price.

Customer annual demand determines the form of delivery of the hydrogen product. Low demands can be serviced with compressed gas cylinders. However, this delivery is the most expensive in terms of cost per unit volume or per unit weight delivered. As the customer demand increases, liquid hydrogen product becomes the most economical delivered form. Recent improvements in cryogenic storage technology have resulted in a trend towards moving liquid product delivery into market segments that have been historically serviced by compressed gas cylinder sales. There is an effort to convert compressed gas cylinder buyers who require annual volumes as low as one million standard cubic feet (SCF) per annum to the use of liquid hydrogen. The relationship of the form of delivered hydrogen to customer annual demand is illustrated in $\mathrm{Fig}$. 4.

One of the significant potential advantages of magnetic refrigeration applied to hydrogen liquefaction is the ability to provide efficient performance in small-scale liquefiers. The high efficiency, especially in relatively small-scale units, makes it economical to decentralize the distribution system. The result will be a greater penetration of liquid hydrogen sales into the lower ranges of customer demand and ultimately expanded markets. 


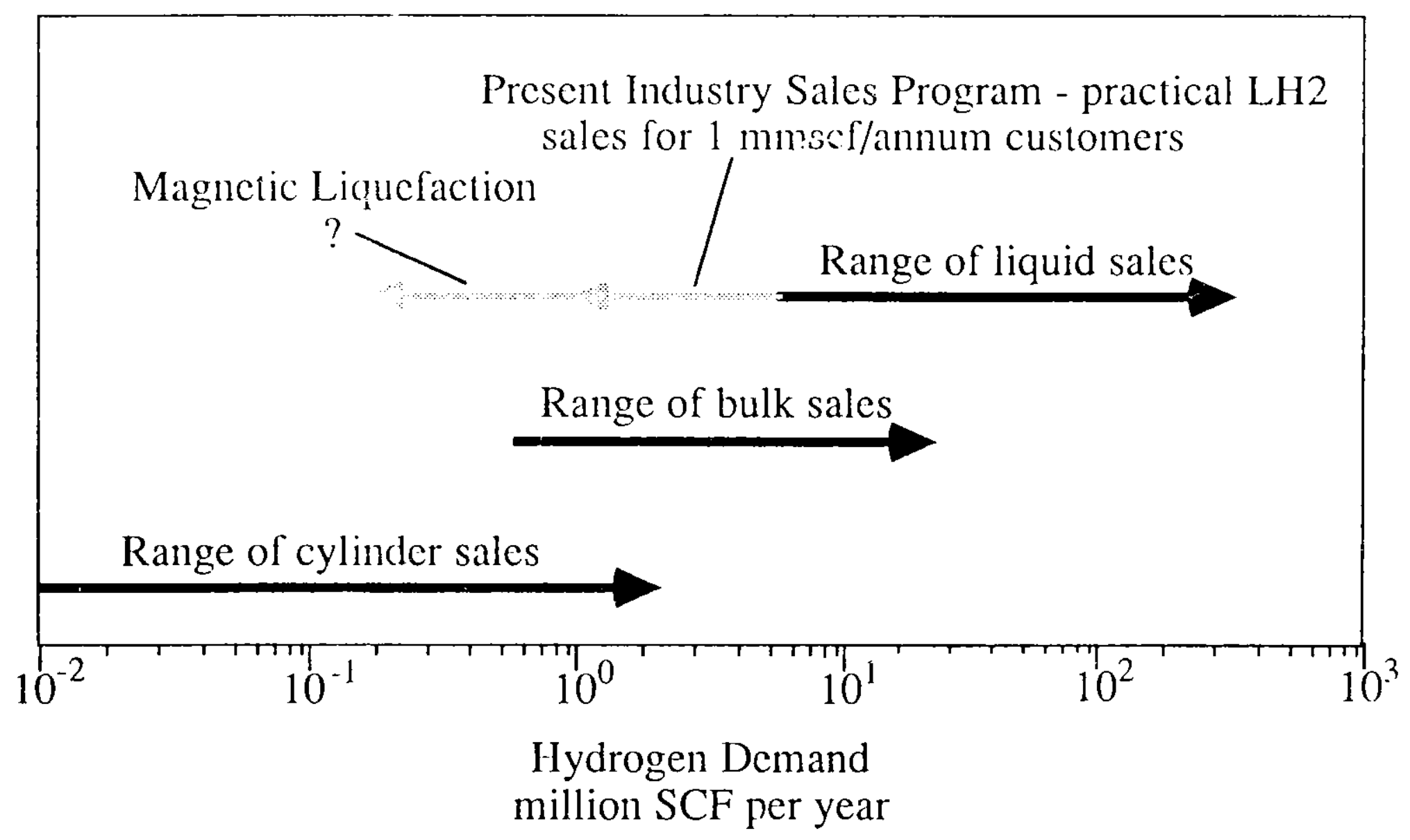

Fig. 4. The relationship of the form of del yered 1 ydrogen to customer annual demand. 


\subsubsection{Feedstock}

Table II presents the relative costs of hydrogen feedstock from a variety of sources. Each of these feedstoc! scurces has constraints that cannot be inferted from the relative cost of hydrogen from each feedstock source.

TABLE II. HYDROGEN FEEDSTOCK SOURCES AND RELATIVE COSTS

Sources of Hydrogen Feedstock

By-Product Caustic Chlorine
Refinery Off-Gas
Steam Reforming of Natural Gas
Steam Reforming of Naphtha
Thermal Decomposition of Methanol
Partia! Oxidation of Coal
Electrolysis of Water

By-Product Caustic Chlorine

Refinery Off-Gas

Steam Reforming of Naphtha

Partia! Oxidation of Coal

Electrolysis of Water

\section{Relative Cost}

1.00

1.50

1.67

2.00

2.17

3.00

4.50

Source: L. Gaumer, Air Products and C:suaicals, Inc.

Hydrogen produced as a by-product from caustic chlorine processes has a relatively low cost. However, the volume production rate from such sources is limited and sources may be geographically distributed in such a way as to preclude their effective coupling with a local or regional market for hydrogen in either gaseous or liquid form.

Hydrogen produced as a refinery off-gas can be obtained in relatively large volumes. There is a high probability that refinery sources would be geographically co-located with a potential hydrogen consumer. However, companies that operate refineries that produce significant amounts of hydrogen as an off-gas often have other chemical products that they manufacture that can make use of this off-gas. Thus a major portion is consumed by a co-located chemical process plant in many instances.

Steam reforming of natural gas is the principal source of industrial hydrogen feed stock. Natural gas is readily available in any geographic location appropriate to matching a production facility with local and regional consumers. Steam reforming of napintha is used advantageously as a feed stock source for on-site generation of hydrogen for chemical process use. Thermal decomposition of methanol also falls in this same category. Both processes can be implemented on a relatively small scale, making them suitable for low volume on-site applications generally. The partial oxidation of coal as a hydrogen feed stock implies two things: large-scale production and 
significant environmental impacts. For this reason this process is not used to any great extent in the production of industrial hydroge' feed stock.

The electrolysis of water offers hydrogen feed stock availability in small scales using equipment that is relatively simple to operate. However, as can be seen from Table II, electrolysisgenerated hydrogen feedstock is the most expensive source. When viewed in light of the premium prices paid for delivered hydrogen by small users, as presented in Tablt III, electrolysis-generated hydrogen feedstock for liquefaction may find some tiches in the merinant hydrogen marketplace. The general promise of magnetic liquefiers, i.e., high efficiency in small-scale systems, is appropriate to considering this type of application.

\section{TABLE III. \\ RELATIVE PRICES BY VOLUME FOR MERCHANT HYDROGEN}

Individual Customer Demand

(Million SCF/yr)
Relative Delivered Price of Hydrogen $\$ / \mathrm{KSCF}$

\begin{tabular}{cc}
0.20 & 7.59 \\
0.35 & 3.93 \\
0.50 & 7.57 \\
0.50 & 3.03 \\
3.0 & 1.10 \\
5.0 & 1.66 \\
10.0 & 1.31 \\
12.0 & 1.26 \\
18.6 & 1.19 \\
22.0 & 0.96 \\
37.0 & 1.10 \\
72.0 & 1.10 \\
97.0 & 0.83 \\
100.0 & 0.79 \\
120.0 & 0.97 \\
150.0 & 1.06 \\
180.0 & 0.83 \\
200.0 & 1.0 \\
& \\
\hline
\end{tabular}

\subsubsection{Liquefaction}

The cost of liquefaction must be considered from two perspectives:

- the capital investment required to construct and bring the liquefaction plant to an operational status; and

- the cost of operation of that liquefaction plant. 
In terms of both these costs accounts, if more efficient, compact, and lower-cost magnetic liquefiers are developed, they will offer significant advantages to users of liquid hydrogen.

Figure 5 illustrates two things. First, it takes about five times more work to produce a unit of cooling power at $20 \mathrm{~K} \mathrm{LH}_{2}$ temperature than it does at $77 \mathrm{~K} \mathrm{LN}_{2}$ temperature. Second, $20 \%$ of the capital cost of a hydrogen liquefier goes into cooling the hydrogen to $77 \mathrm{~K}$, while $80 \%$ of the capital cost goes into achieving the $20 \mathrm{~K}$ stage.

Compact, low-cost magnetic refrigeration applied to the $80 \mathrm{~K}$ to $20 \mathrm{~K}$ stage offers the opportunity for achieving significantly lower capital investments than those presently made in mechanical refrigeration systems operating over the same temperature range. This is the principal mechanism of impact of magnetic refrigeration on capital investments costs.

The consideration of efficiency does not enter into capital investment costs. However, it is the dominant consideration in operating costs. Table IV clearly illustrates the dominance of electric power costs in the operating costs budget.(31) Liquid hydrogen has often been referred to as "liquid electricity."

TABLE IV.

\section{OPERATING COSTS OF AN 850 T/D HYDROGEN \\ LIQUEFACTION SYSTEM}

\section{Cost Items}

Electric Power

Labor, Administration, and Overhead

Chemicals, Supplies, Water, Taxes, and Insurance

Total

\section{$\%$}

75.2

4.0

20.8

100.0

It is in the operating costs account of small liquefiers, less than about 2 tons per day, that the potential impact that magnetic refrigeration will be most significant. In addition, high thermal efficiency, and thus low electrical power requirements, are potential attributes of both large-scale and small-scale magnetic refrigerator units. This characteristic cannot be matched by mechanical refrigeration systems which rapidly lose efficiency as the scale of implementation of these production facilities is decreased. In addition to the potential for significant reduction in power costs, it is to be expected that a magnetic-refrigeration-based system will require less operill!! labor and supervision cosıs, lower administrative and overhead costs, lower operating supplies $: 11,1$ 


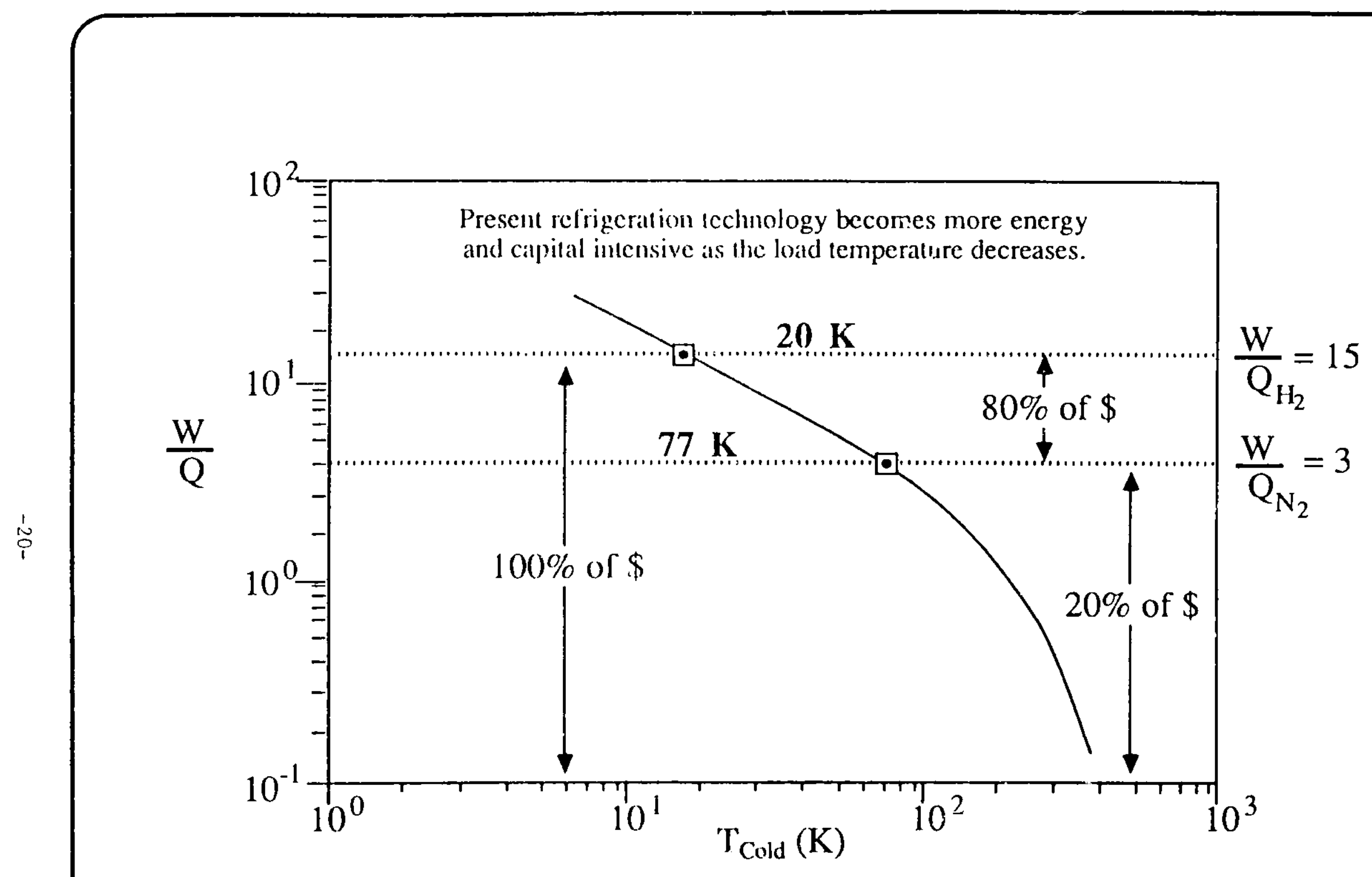

Fig. 5. Capital investment distribution in present liquefaction plants as proportioned to the work distribusion over the sefrigeration and liquefaction temperature range. 
maintenance costs, and finally lower taxes and insurance costs (which are usually computed on a percent of investment cost basis).

Thus it is probable that magnetic-refrigeration-based hydrogen liquefaction systems will be characterized by significantly lower capital investment cost and operating costs. Further, this potential advantage will be available in both large-scale and small-scale installations.

\section{LIQUEFACTION OF HYDROGEN}

\subsection{Gas-Cycle Liquefiers}

Hydrogen is conventionally liquefied using the same cycles used to liquefy helium.(32) The Claude cycle is the basis of most hydrogen and helium liquefaction plants. Figure 6 shows a typical gas cycle hydrogen liquefier. Liquid nitogen $\left(\mathrm{LN}_{2}\right)$ or a comparabis refrigerator is used to precool the hydrogen, allowing the compr:ssors to operate at $300 \mathrm{~K}$ rather than $80 \mathrm{~K}$. Otherwise, the Claude cycle is at the heart of the liquefaction process shown. The basic process stream of gaseous hydrogen $\mathrm{GH}_{2}$ is precooled in heat exchanget 1 , then split three times to provide precooling by two turbines and J-T expanders. The main stream is put through three heat exchangers and an ortho-topara converter (a further discussion of ortho and para-hydrogen is presented below) to produce $\sim 100 \%$ para hydrogen at $20.4 \mathrm{~K}$. The $\mathrm{GH}_{2}$ flows split from the main stream are recirculated and combined with makeup gas to complete the loop.

The Claude cycle is the superposition of the Linde (Hampson) cycle and the Brayton (Joule) cycle. The Linde or Hampson cycle essentially uses a Joul - -Thomson (J-T) refrigerator in which liquid is drawn off after the J-T valve and make-up gas is added before the compressor. The Brayton or Joule cycle is essentially the Linde cycle in which the J-T valve is replaced by an expander. For a more detailed explanation of conventional gas liquefiers, see reference 33.

There are numerous variations on the design of gas-cycle liquefiers, depending upon the choices of the manufacturer. Those choices are based on cost, captive technology, size of unit, reliability, availability, cooling power, along with personal choice, etc. For instance, the compressors may be screw or turbine or scroll or even reciprocating units, depending upon size. The expanders can be reciprocating or turbine units and the turbines might have oil bearings or gas bearings, etc. In some cases, hydrogen liquefiers are made by using a heliurn refrigerator with an external hydrogen gas process stream. In other cases, the hydrogen gas to be liquefied is also the working fluid of the liquefier. With all of these choices, the exact cooling power, capital cost, efficiency, reliability, etc., of a hydrogen liquefier depends upon detailed knowledge of the specific liquefier. For the purpose of this study, however, the gas-cycle liquefier used as a basis for 


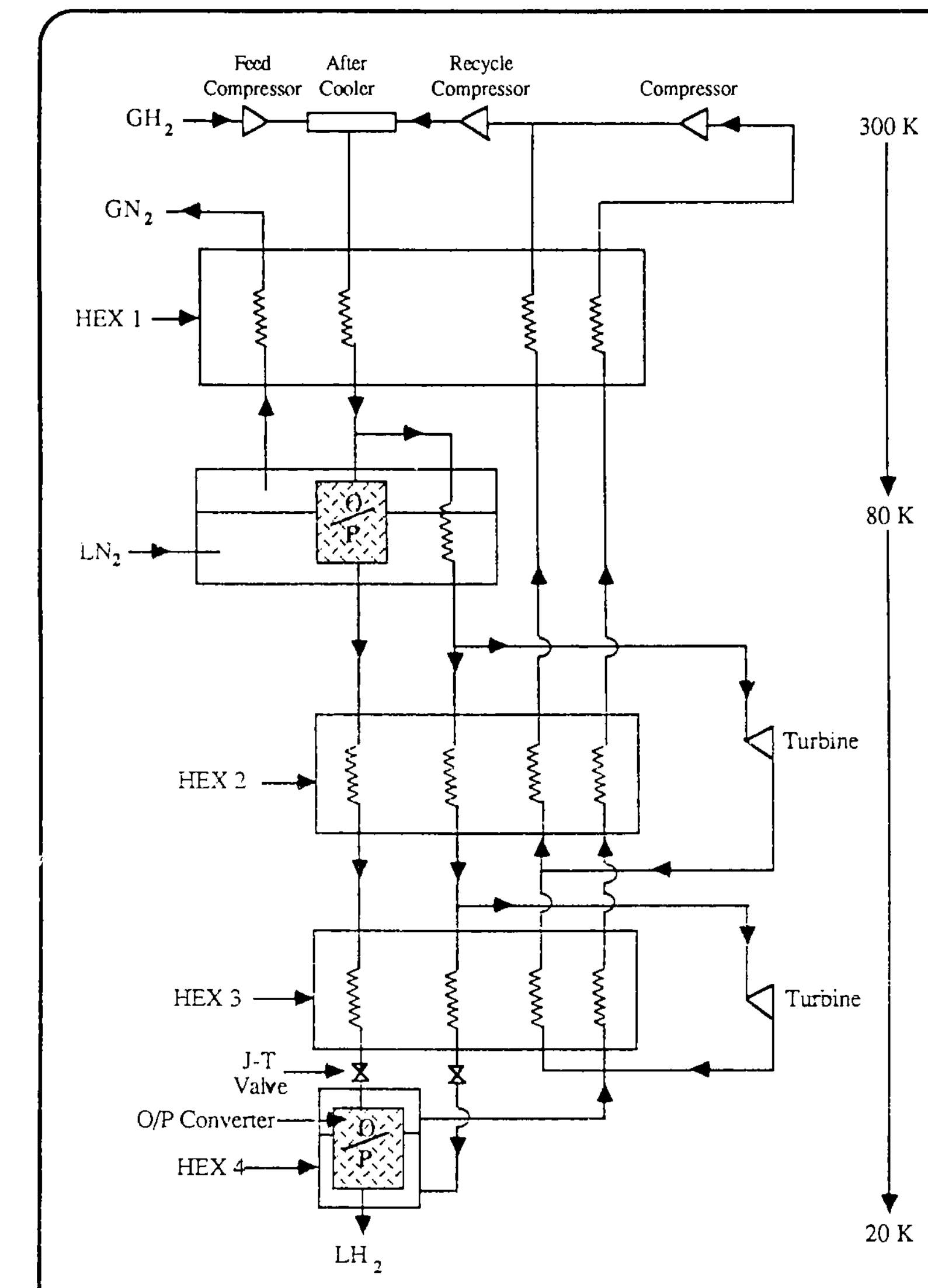

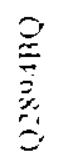

Fig. 6. Typical gas cycle hydrogen liquefier. 
comparison to a magnetic liquefier is only an average unit, i.e., a generic Claude-cycle unit which is close to state of the art. The efficiency of gas-cycle liquefiers varies slightly with designs above 5 tons per day $(\mathrm{V} / \mathrm{d})$ to $30 \mathrm{~V} / \mathrm{d}$, the relative Camot efficiency of the liquefier is $20-25 \%$. The capital costs and operating costs of hydrogen liquefiers is such that gas-cycle plants smaller than about $5 \mathrm{t} / \mathrm{d}$ are not economically feasible.(27)

The liquefaction of hydrogen imposes a unique additional complication in that the hydrogen molecule exists in different forms. A high-energy ortho $(\mathrm{O})$ state and a low-energy para $(\mathrm{P})$ state exist depending on whether the nuclear spins of the protons are aligned or anti-aligned, respectively. Above about $20 \mathrm{~K}$ there is a significant quantity of ortho-hydrogen in an equilibrium state, the amount increasing with temperature from about $0.2 \%$ at $20 \mathrm{~K}$ to $50 \%$ at $77 \mathrm{~K}$ to about $75 \%$ at $300 \mathrm{~K}$. Because of the relatively slow natural conversion rate and because of the large amount of energy given off during the conversion, catalytic converters are used at various temperatures in liquefaction plants. One converter at $77 \mathrm{~K}$ provides good efficiency for $\mathrm{O}$ to $\mathrm{P}$ conversion from 300 $\mathrm{K}$ to $77 \mathrm{~K}$. Several more converters are required to achieve high efficiency between $77 \mathrm{~K}$ and $20 \mathrm{~K}$.

\subsection{Magnetic-Cycle Liquefiers}

Given that typical gas-cycle liquefiers presently are not cost-effective below about $5 \mathrm{t} / \mathrm{d}$ and given that there appears to be a market for a 1-2 t/d hydrogen liquefier, the obvious question is to address whether a magnetic liquefier is cost effective at the $1-2 \mathrm{t} / \mathrm{d}$ size.

With this in mind, a magnetic-cycle liquefier composed of a liquid nitrogen heat sink and precooler plus a $77 \mathrm{~K}$ to $20 \mathrm{~K}$ magnetic refrigerator is the simplest unit to compare to a conventional gas-cycle liquefier. The boiled-off nitrogen gas ( $\left.\mathrm{GN}_{2}\right)$ at $77 \mathrm{~K}$ can be used to precool the incoming hydrogen process stream from $300 \mathrm{~K}$ to near $77 \mathrm{~K}$ in a counterflow heat exchanger. There is ample sensible heat available from the nitrogen gas evolved by the magnetic stage to precool the hydrogen stream. The excess sensible heat in $\mathrm{GN}_{2}$ could be used to cool thermal shields which intercept radiant energy normally incident on lower temperature structures. The O-to-P conversion to obtain equilibrium hydrogen at $77 \mathrm{~K}$ before entering the $77 \mathrm{~K}$ to $20 \mathrm{~K}$ magnetic stage can occur in a single converter in the $\mathrm{LN}_{2}$ tank. (It can be shown that there is negligible benefit in doing the O-to-P conversion in more than one stage above $77 \mathrm{~K}$.)

Our computations indicate that a $1 \mathrm{t} / \mathrm{d}$ hydrogen liquefier would boil off about $27 \mathrm{t} / \mathrm{d}$ of $\mathrm{LN}_{2}$. The location of the $\mathrm{LN}_{2}$ supply is a factor in the ultimate cost of $\mathrm{LH}_{2}$ produced by the magnetic liquefier. Whether it is more economical to truck in this quantity of $\mathrm{LN}_{2}$, or to produce it on site is bcyond the scope of this report. For cost comparisons we have taken delivered $\mathrm{LN}_{2}$ prices. 


\subsubsection{Magnetic Refrigerator Design Options}

The design of a magnetic refrigerator (MR) involves selecting design parameters for each major component of the system. The rational for various selections is presented in subsequent subsections.

The design of an MR begins with the primary specifications of the intended application: for example, the load to be cooled, the temperature at which the load is to be cooled, and the sink temperature and method of rejecting heat from the MR. The objectives for this study specified a heat rejection temperature of $77 \mathrm{~K}$ provided by vaporization of $\mathrm{LN}_{2}$. Thus, the $\mathrm{MR}$ must cool $\mathrm{H}_{2}$ from $77 \mathrm{~K}$ to $20.27 \mathrm{~K}$ and liquefy it at a rate of $1 \mathrm{t} / \mathrm{d}$ with heat rejection to boiling $\mathrm{LN}_{2}$. The first choice to be made in the design of a MR for this application involves the refrigeration cycle.

\subsubsection{Refrigeration Cycle}

A suitable thermodynamic refrigeration cycle must be performed to use the magnetocaloric effect in a refrigerator. The MR may be designed to operate with one of several possible cycles as summarized in Fig. 7; each cycle has advantages and disadvantages for particular operation conditions. Some of the differences in the suitability of various cycles at different operating temperatures can be illustrated by considering the "adiabatic temperature change." The ariabatic temperature change upon magnetization or demagnetization is given by

$$
\Delta T_{S}=-T \int_{B_{i}}^{M}\left(\frac{1}{C_{B}}\right)\left(\frac{\partial M}{\partial T}\right)_{B} d B
$$

where $C_{3}$ is the heat capacity at constant flux censity, $M$ is the masnetization, and $B$ is the external flux density. Because the adiabatic temperature change is inverseiy proportional to $C_{B}$, which increases sharply above about $20 \mathrm{~K}$, appreciable $\Delta \mathrm{T}_{\mathrm{S}}$ can only be obtaineu' by a large $\delta \mathrm{M} / \delta \mathrm{T}$ above $\sim 20 \mathrm{~K}$. Therefore, the materials required for thermodynamic cycles are paramagnets below $-20 \mathrm{~K}$ and ferromagnets above $\sim 20 \mathrm{~K}$. The thermodynamic cycles differ somewhat above and below $\sim 20$ $\mathrm{K}$ because of the change in $\mathrm{C}_{\mathrm{B}}$. The magnetic cycles shown in Fig. 7 are analogous to gas cycles. A general description of tinese cycles is given below.

4.2.1.1.1 Carnot Cycle. The Carnot cycle consists of two isothermal processes and two isentropic processes that are easy to perform in a magnetic system. Consider a ferromagnetic material near its Curie temperature: the material can be isolated from, or put in contact with, hot and cold baths at will. The first step is an iosthermal magnetization while the 
material is in contact with the hot bath; the heat of magnetization is rejected into the hot bath. Next, an isolated (isentropic) partial demagnetization cools the material. The third step puts the material in contact with the cold bath while demagnetization continues to zero field, and heat is absorbed from the cold bath. The final step is an isentropic partial magnetization back to the original starting temperature. These two isothermal processes and two isentropic processes constitute a magnetic Carnot cycle as shown in Fig. 7. The temperature span of a Carnot cycle above about $20 \mathrm{~K}$ is limited to $5-10 \mathrm{~K}$ with about $10 \mathrm{~T}$ field change, but no regeneration is required. Larger temperature spans require other cycles.

4.2.1.1.2 Brayton Cycle. The Brayton cycle consists of two isentropic processes and two isofield processes. With regeneration it can cover much larger temperature spans than a Carnot cycle. The Brayton cycle is very attractive because it can be coupled easily to the external heat exchanger through the temperature change caused by the isentropic field changes, as illustrated in Fig. 7.

4.2.1.1.3 Ericsson and Stirling Cycles. An Ericsson cycle consists of two isothermal processes, and two isonield processes (Fig. 7). The Stirling cycle requires two isothermal processes and two isomagnetization processes as shown in Fig. 7. Both cycles require regeneration to span large temperature differences. These cycles require excellent heat transfer between the heatexchange fluid and the source and sink to attain the isothermal process. Thus, the Brayton cycle is easier to implement in a practical device.

\subsubsection{Magnetic Materials}

To execute any thermodynamic refrigeration cycle, an entropy change must occur. For magnetic cycles, the entropy change is caused by the application or removal of a magnetic field to a paramagnetic or ferromagnetic material. Generally, paramagnets are used below, and ferromagneis are used above $-20 \mathrm{~K}$.

The criteria for selection of ferromagnets and paramagnets are similar with regard to themal, chemical, physical, and mechanical properties. A summary of these criteria is presented in Table V.

Based on the above criteria, gadolinium compounds are among the best initial choices as magnetic refrigerants. Gadolinium may be made into a wide variety of ferromagnetic compounds with transition temperatures ranging from below $20 \mathrm{~K}$ to near $300 \mathrm{~K}$. For the present study, the thermomagnetic properties of $\operatorname{Er}_{x} \mathrm{Gd}_{(1-x)} \mathrm{Al}_{2}$ have been calculated using mean-field theory for the magnetic properties and the Debye model for the thermal properties. The value of $x$ was chosen to provide an ordering temperature of $85 \mathrm{~K}$, as required. The calculated properties are estimated to be 

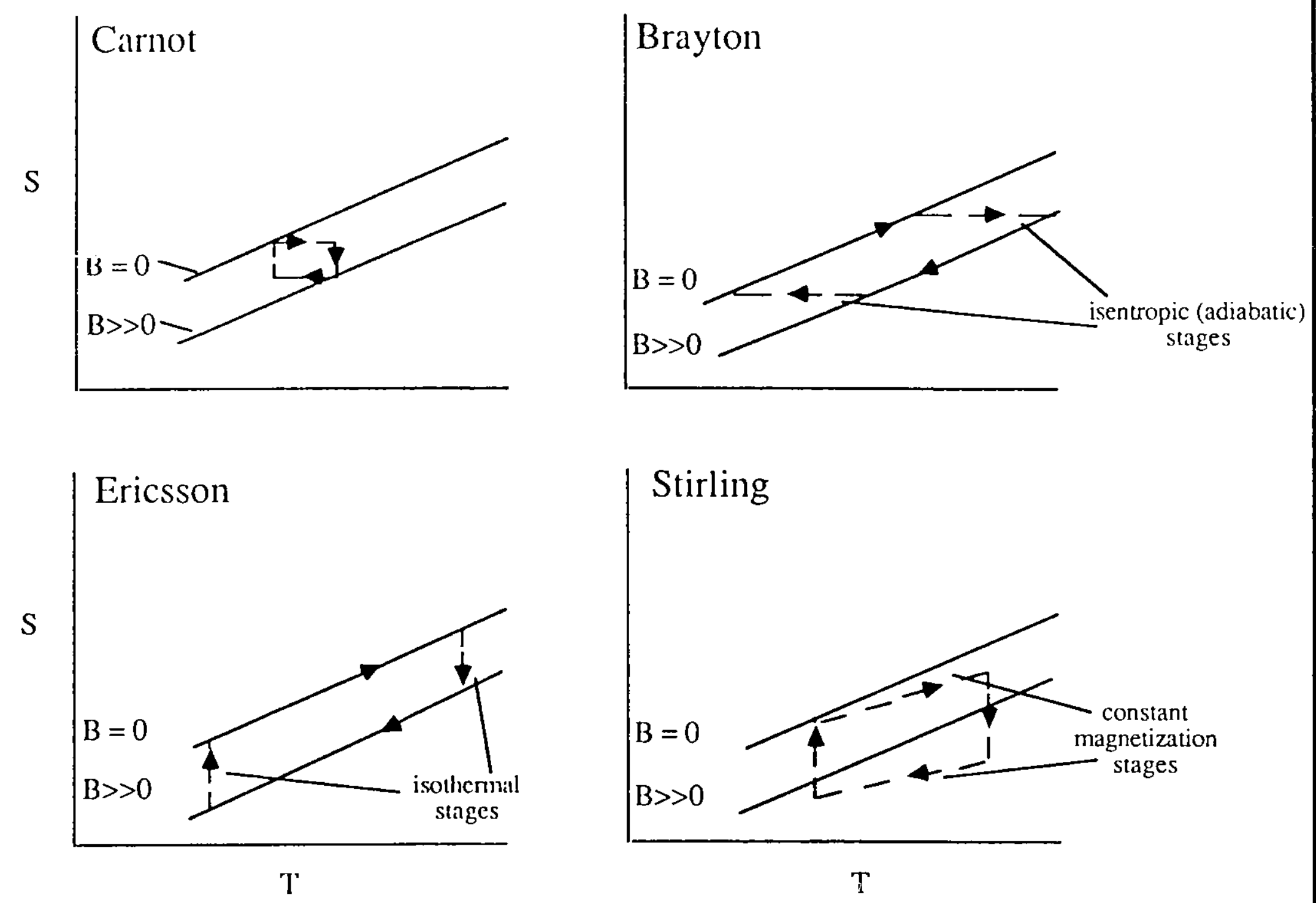

Fig. 7. Magnetic entropy-temperature diagrams illustrating several thermodynamic cycles with ferromagnetic materials. 
accurate to $10-20 \%$. Blending of these or similar compounds can be done to provide close to ideal materials for actual cycles.

TABLE V.

CRITERIA FOR SELECTION OF MAGNETIC MATERIALS

\author{
MAGNETIC PROPERTIES \\ - Small Magnetic Hysteresis \\ - $\quad$ Large Magnetic Moment \\ - Large Entropy Change with Field \\ CHEMICAL PROPERTIES \\ - $\quad$ Easy Preparation \\ - Stability to Oxidation \\ - Non-Poisonous \\ THERMAL PROPERTIES \\ - Low Heat Capacity \\ - $\quad$ High Thermal Conductivity \\ - Low Thermal Expansion \\ PHYSICAL PROPERTIES \\ - High Magnetic Ion Density \\ - Small Molar Volume \\ MECHANICAL PROPERTIES \\ - High Young's Modulus \\ - High Tensile Strength \\ - Good Machinability \\ ECONOMICS/AVAILABILITY \\ - Relatively Low Cost \\ - Plentiful Sources
}

\title{
4.2.1.3 Heat Exchange
}

All refrigerator working materials (i.e., gas, liquid, or solid) need some form of regeneration or recuperation in order to span a large temperature difference between the temperature of the load being cooled and the heat sink temperature at which heat is rejected. This function is performed by the counterflow heat exchangers in a gas Claude cycle and by an external regenerator in the gas Stirling cycle.

Recuperation is a heat exchange process in which heat is continuously transferred between two bodies. Regeneration is a periodic heat exchange process in which sensible heat is stored and released in different parts of a cycle. Regeneration, in general, requires a much higher working fluid 
flow rate and a larger mass for the regenerator than are required for recuperation. Active magnetic regeneration (AMR) is a unique feature of magnetic refrigerators MRs in which the magnetic material serves as both the working material and as the regenerator matrix.

High efficiency requires excellent heat transfer during regeneration because the heat transferred during the two regenerative parts of the cycle is much larger than the heat transferred to or from the external heat exchangers. This point is illustrated qualitatively for a magnetic Brayton cycle in Fig. 8. The area $Q_{C}$ is the heat that flows from the load near $\mathrm{T}_{\mathrm{C}}$ to the magnetic material; the area $\mathrm{Q}_{H}$ is the heat that flows from the magnetic material to the heat sink near $\mathrm{T}_{\mathrm{H}} ; \mathrm{QR}_{\mathrm{R}}$ is the heat that must be transferred in each of the regenerative parts of the cycle. The relative size of the areas illustrates that the effects of irreversibility in handling $Q_{R}$ could be comparable to $Q_{C}$ and result in very low efficiency.(34)

\subsubsection{Magnetization/Demagnetization}

Magnetization and demagnetization of the working material can be accomplished by:

- sharging or discharging the magnet;

- moving the magnetic material by rotary motion, reciprocal motion, or rotation of an magnetically anisotropic material or anisotropically shaped material;

- moving a magnet by rotary or reciprocal motion; and

- moving a magnetic shield.

Each of these will now be discussed in more detail.

The ability to charge and discharge a magnet rapidly and efficiently offers a potentially. exciring magnetic refrigerator design. The charging and discharging of the magnet allow's the magnetic material to remain fixed, which simplifies all of the plumbing and eliminates seal problems. Also, the work is provided electrically, which is more efficient than converting electrical energy to mechanical motion to move the magnetic material. One disadvantage of this type of refrigerator is that low-inductance coils (that can be charged and discharged at rates of $\sim \mathrm{Hz}$ ) require a high current. Because of the Joule heating in the magnet leads ai high current, the overall efficiency will drop. Also, the energy required to produce the magnetic field is several times larger than the energy required to magnetize the working material so the ac-to-dc convertor supplying and receiving the power must be very efficient. Large changing magnetic flux will induce large eddy currents in much more of the magnetic refrigerator parts than in designs where the magnetic field is constant. 


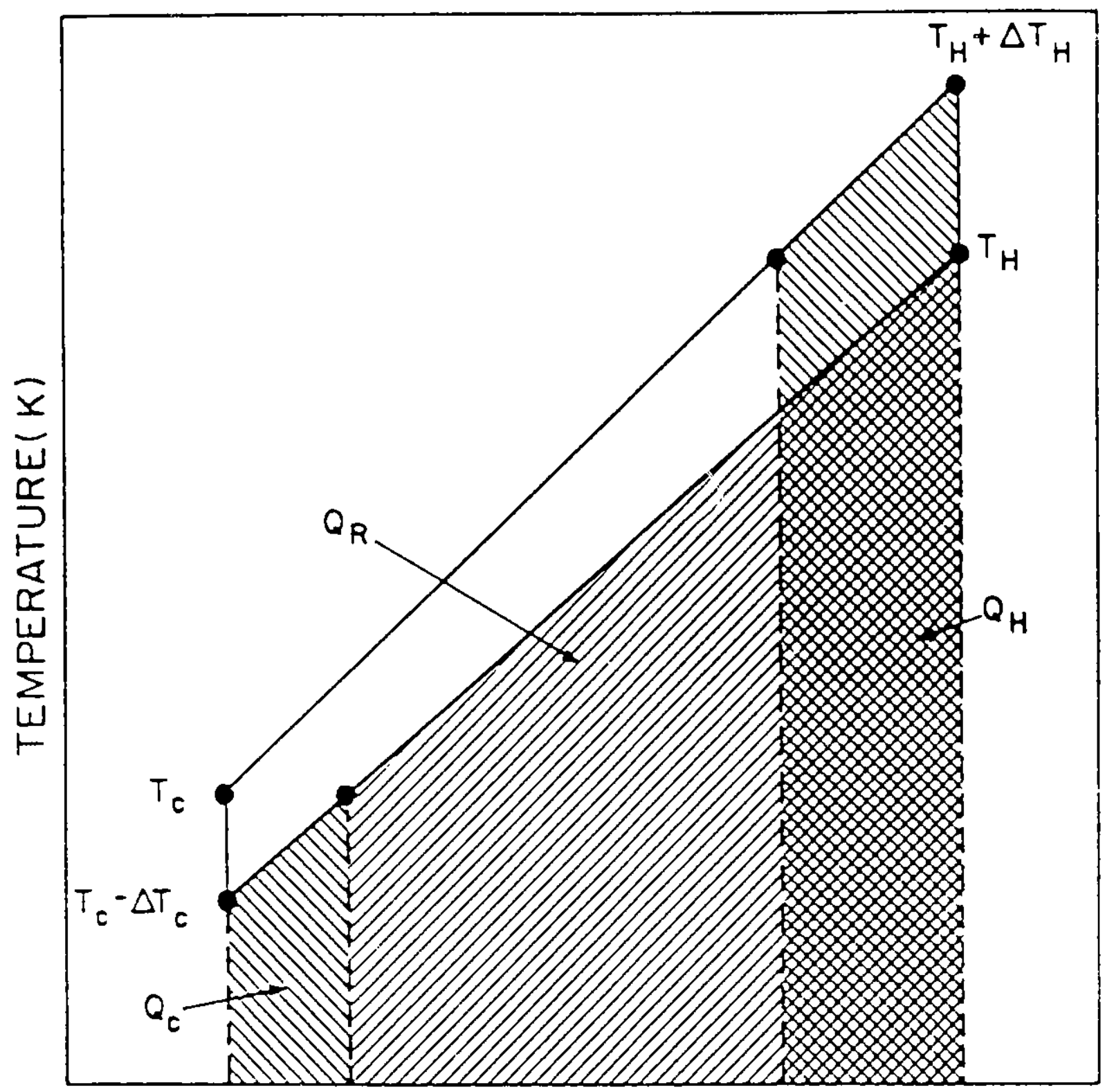

ENTROPY $(\mathrm{J} / \mathrm{kg} \cdot \mathrm{K})$

Fig. 8. Entropy-temperature diagram for typical ferromagnet that illustrates the relative magnitudes of heat flow in different parts of the cycle. 
A second option for magnetization and demagnetization involves movement of a magnetic material through the magnetic field The motion of the magnetic material through the fixed field may be either reciprocal or rotary. Several difficulties with reciprocal magnetic material motion designs are:

the large magnetic forces that must be balanced as the magnetic material enters and exits the magnetic field at different temperatures;

- the need for excellent heat transfer to the magnetic material while it is both in and out of the magnetic field (and in some cases while entering or leaving the magnetic field);

- the cooling and heat rejection processes are intermittent; and

- the momentum of stopping, reversing direction, and starting the motion of the magnetic material.

The first and third of these drawbacks can be somewhat alleviated by multiple magnetic material sections so that one section is entering the magnetic field while another is leaving. This reduces the input force requini, but doubles the compressive force between the two sections. The reciprocal motion of two sections also tends to give a long, slender geometry unless the material is moved in a circular reciprocating (oscillation back and forth) motion.

Rotary motion of magnetic material can be accomplished by a wheel geometry. A torus of magnetic material rotated through a magnetic field has the advantages of more easily reacted magnetic forces on different pars of the torus and continuous refrigeration. However, provisions must be made to prevent the working fluid from rotating with the magnetic material, and the working fluid must flow through, rather than around, the magnetic material. The seals for flow' control in a rotating wheel housing assembly may be difficult. Several seal options exist.

In a third option for magnetization and demagnetization, flat sheets of a ferromagnetic material exhibit a demagnetization factor approaching unity when the 1lat surface of the material is perpendicular to the direction of a magnetic field and approaches zero when the plane of the sheets is parallel to the direction of the applied magnetic field. As the material rotates with the plane of magnetic material alternating between aligned and perpendicular to the field, the demagnetization factor creates an internal field which alternates between B applied and approximately zero. The demagnetizing field is typically limited to about $2 \mathrm{~T}$ by intrinsic material properties. The low demagnetizing field is not appropriate for high-cooling-power MRs. In addition, the sheets of magnetic material must be separated sufficientl'; to not compromise the demagnetizing effects, hence, they make ineffective use of the magnet volume. 
Another altemative is to rotate a magnetically aniso'ropic material in a stationary magnetic field or rotate the magnet and keep the material stationary. In either case, the material has an easy magnetization axis which, when aligned with the field, results in a larger magnetization. When the axis is perpendicular to field, the magnetization is small. These materiais must be used in single crystal form, are less common than isotropic ferromagnets, and typicaliy demonstrate magnetostriction which can lead to design problems.

Finally, magnetization and demagnetization of the magnetic material can be achieved by moving a shield with a high magnetic permeability between the magnet and the material. This magnetic shield adds mass to the MR, increases the space between the magnetic material and the magnet, creates external field fluctuations, and results in large unbalanced forces. Thas option is not ver viable for practical designs.

\subsubsection{Magnet Configuration}

The efficiency of an MR critically depends on the adiabatic temperature change of the magnetic material being as large as possible over as wide a temperature span as possible. In the range of interest the adiabatic temperature change is proportional to the applied magnetic field (to a limit); therefore a superconducting magnet is used to obtain the highest practical magnetic field. Superconducting magnet technology using NbTi wire is well established for fields up to $\rightarrow \mathrm{T}$. The possibility of higher fields exists using multifilamentary $\mathrm{Nb}_{3} \mathrm{Sn}$ wire but at considerably more expense and development risk.

The following magnet configurations are useful in MR designs:

- solenoid, such as right circular, or bent (circular arc);

- Helmhol:z-like pair;

- racetrack; and

- toroid with gap.

The right circular solenoid and Helmholtz-like pair magnets are the easiest to fabricate, while the others (especially the continuous toroid) are significantly more difficult to fabricalc. Also, in many cases the superconducting windings are distributed away from the magnetic material and contribute little to the useful field. The advantage of the toroid is that the field outside a complete toroid is zero and if a relatively narrow gap were cut, the resulting stray field would be very small. Split wheels, split bearings, or rim drives may be required for some configurations such as a toroid of magnetic material rotating through the bore of a solenoidal magnet. Otier areas of concern in the choice of a magnet configuration include: 
- $\quad$ field profile (the shape of the magnetic field);

- flux return (to reduce stray fields);

- current leads for charging (and discharging) the magnet;

- cooling of the magnet (pool boiling of LHe, for example);

- magnetic forces between the magnet and the magnetic material, and between magnets where more than one magnet is involved; and

- persistent mode switch operation.

A solenoidal magnet configuration was selected for the magnetic liquefier because of its high field in the bore and its ease of fabrication.

\subsubsection{Heat Sink}

Many times the quantity of heat removed from a load at low temperature must be pumped to a sink at a higher temperature in any refrigerator. Several options exist for a heat sink for an MR:

- melting and/or boiling of a solid or liquid;

- a gas-cycle refrigerator which in turn rejects its heat to ambient air or cooling water; and

- direct heat exchange to ambient.

In this study, the MR heat sink configuration specified for the magnetic liquefier is boiling $\mathrm{LN}_{2}$.

\subsubsection{Source/Sink Connection}

The heat load and heat sink may be connected to the MR by conduction, convection, or hea: pipes. High-thermal-conductivity materials such as Oxygen Free High Conductivity (OFHC) copper may be attached to the heat load and heat sink and thermally connected to the magnetic material in such a way that when the magnetic material is magnetized, the heat of nageetization is conducted to the sink; and when the magnetic material is demagnetized and cools, heat is conducted from a load to the magnetic material. The use of conduction for this process generally requires a close coupling between the MR, the load, and the sink to minimize the temperature differential through the conductor. However, no circulating fluid (and thus, no pump) is needed in contrast to the convection method. The conduction heat transfer coefficient is generally smaller than that for convection so generally conductive designs are more quickly limited by the heat transfer surface area of the magnetic material. 
The convection inethod was selected for the magnetic liquefier because it provided much higher heat fluxes than conduction. Gaseous $\mathrm{He}$, at about $1 \mathrm{MPa}$ pressure, can be circulated through the magnetic material and through the heat exchangers for both the load and the heat sink. In contrast to hydrogen, helium at tiese teniperatures and pressures is a single-phase coolant, thereby providing the simplest design.

\subsubsection{Active Magnetic Regenerative (AMR) Liquefier}

Several magnetic cycles were carried through the conceptual stage before settling on the active magnetic regenerative refrigerator. The first candidate magnetic liquefier design is based on a recuperative Brayton cycle which can span the temperature range. This option has been explored by $\mathrm{ACA}$ in the $20 \mathrm{~K}$ to $80 \mathrm{~K}$ range in detail in a previous internal study. In this case, a continuous flow of magnetic material is necessary. Magnetic material is demagnetized at the cold end, absorbing heat, and it is magnetized at the hot end, rejecting heat. The magnetized material exchanges heat with the demagnetized material in their respective flows from the hot to cold and cold to hot sides of the refrigerator. Because direct heat exchange between solids is difficult, an intermediate heat transfer fluid, helium, is used. Analysis indicates that the performance of a recuperative device is good. Overall efficiency in the 50-60\% range is possible with 3 to 4 intermediate stages (a good number from the point of view of efficiently removing the sensible heat and O-P heat). The device has potential flow control problems with the heat transfer fluid, however, which cannot be eliminated in a mechanically simple way (for more details on flow control problems see, for example, reference 23). Without a good solution to this problem, this unit was not pursued any further.

A second candidate design reviewed was a regenerative Brayton cycle with an external regenerator. In this device, an intermediate thormal mass or regenerator is used to regenerate the magnetic material in going from the hot to the cod end in the magnetized state and from the coid to the hot end in the demagnetized state. In the $20 \mathrm{~K}$ to $80 \mathrm{~K}$ range, only solid regenerators are possible because no liquids exist over the whole temperature range and gases have very limited enthalpy content. This unit is analogous to the one developed by G.V. Brown(26) except the liquid alcohol/water regenerator must be replaced by a solid. Again, an intermediate heat transfer fluid is necessary. Because the extemal regenerator must have large thermal mass compared to the working magnetic material, and excellent heat transfer between the regeneration solid and magnetic material is required for good efficiency, the heat flow mechanism becomes a limiting process. (The Japanese are building a low-power unit based on this concept using conductive GHe as the heat transfer medium. No results have been formally published yet.) 
The final design considered and the one chosen for this study is not based on a single cycle but rather a very large number of cooperative Brayton cycles connected together in a serial fashion by a heat transfer fluid which flows in one direction along the individual cycles when they are demagnetized and in the opposite direction when the cycles are magnetized. The device which embodies this thermodynamic curiosity is called the Active Magnetic Regenerator (AMR), shown in Fig. 9. The packed bed of magnetic material is sandwiched between a hot and cold reservoir with a heat transfer fluid (helium) which can flow from the hot to cold reservoir and vice versa through the bed. The operation of the AMR is simple: the bed is magnetized with no flow. Fluid is then passed from the cold to the hot reservoir with the bed in the magnetized state. The bed is then demagnetized with no flow. Fluid is then passed from the hot to the cold reservoir with the bed in the demagnetized state, completing the cycle. Figure 10 shows the resulting temperature profiles for the magnetic material and the fluid, assuming the bed thermal mass is infinitely large. If the bed thermal mass is finite, the bed and fluid temperature profiles change over the blow periods. The fluid entering the cold heat exchanger ( $\mathrm{CHEX}$ ) during the cold blow enters it at a temperature $\Delta \mathrm{T}_{\text {cold }}$ below the temperature of the heat exchanger. It is simple to see that the resulting heat absorbed by the gas is given by

$$
\dot{\mathrm{Q}}_{\text {cold }}=\dot{\mathrm{m}} \mathrm{f}_{\mathrm{p}} \Delta \mathrm{T}_{\text {cold }}
$$

The same argument can be used to obtain the expression for $\dot{Q}_{\text {hot }}$

Previous analysis of the AMR has shown that its performance is strongly dependent on the magnetic material properties. (34) The ideal AMR material is one in which the adiabatic temperature change with field is proportional to the absolute temperanre. This is the result of constant heat capacity in the heat transfer fluid and the second law of thermodynamics. As seen in equation (2), in a closed-cycle AMR, $\dot{\mathrm{m}}_{\mathrm{f}}$ is constant at both the hot and cold ends of the unit and because $\mathrm{C}_{\mathrm{p}}$ of the GHe is also temperature-independent, $\dot{Q}_{C}$ is proportional $\Delta \mathrm{T}_{\mathrm{C}}$. For the hot end, $\dot{\mathrm{Q}}_{\mathrm{H}}$ is proportional to $\Delta \mathrm{T}_{\mathrm{H}}$. Therefore, because the ratio of $\dot{\mathrm{Q}}_{\mathrm{H}}$ to $\dot{\mathrm{Q}}_{\mathrm{C}}$ is $\mathrm{T}_{\mathrm{H}}$ to $\mathrm{T}_{\mathrm{C}}$ by the second law, the ratio $\Delta \mathrm{T}_{\mathrm{H}}$ to $\Delta \mathrm{T}_{\mathrm{C}}$ must be $\mathrm{T}_{\mathrm{H}}$ to $\mathrm{T}_{\mathrm{C}}$. This requirement is in contrast to a recuperative external regenerative magnetic refrigerator in which the ideal material is one with a constant adiabatic temperature change over the temperature range of the device. It has been shown $(34,35)$ thit if a naterial with a constant adiabatic temperature change is used in the AMR in the $20 \mathrm{~K}$ to $80 \mathrm{~K}$-omperature range, an AMR starting at $80 \mathrm{~K}$ will not cool much below $50 \mathrm{~K}$ with no load. For proper performance, the adiabatic temperature change must be proportional to the temperature. 


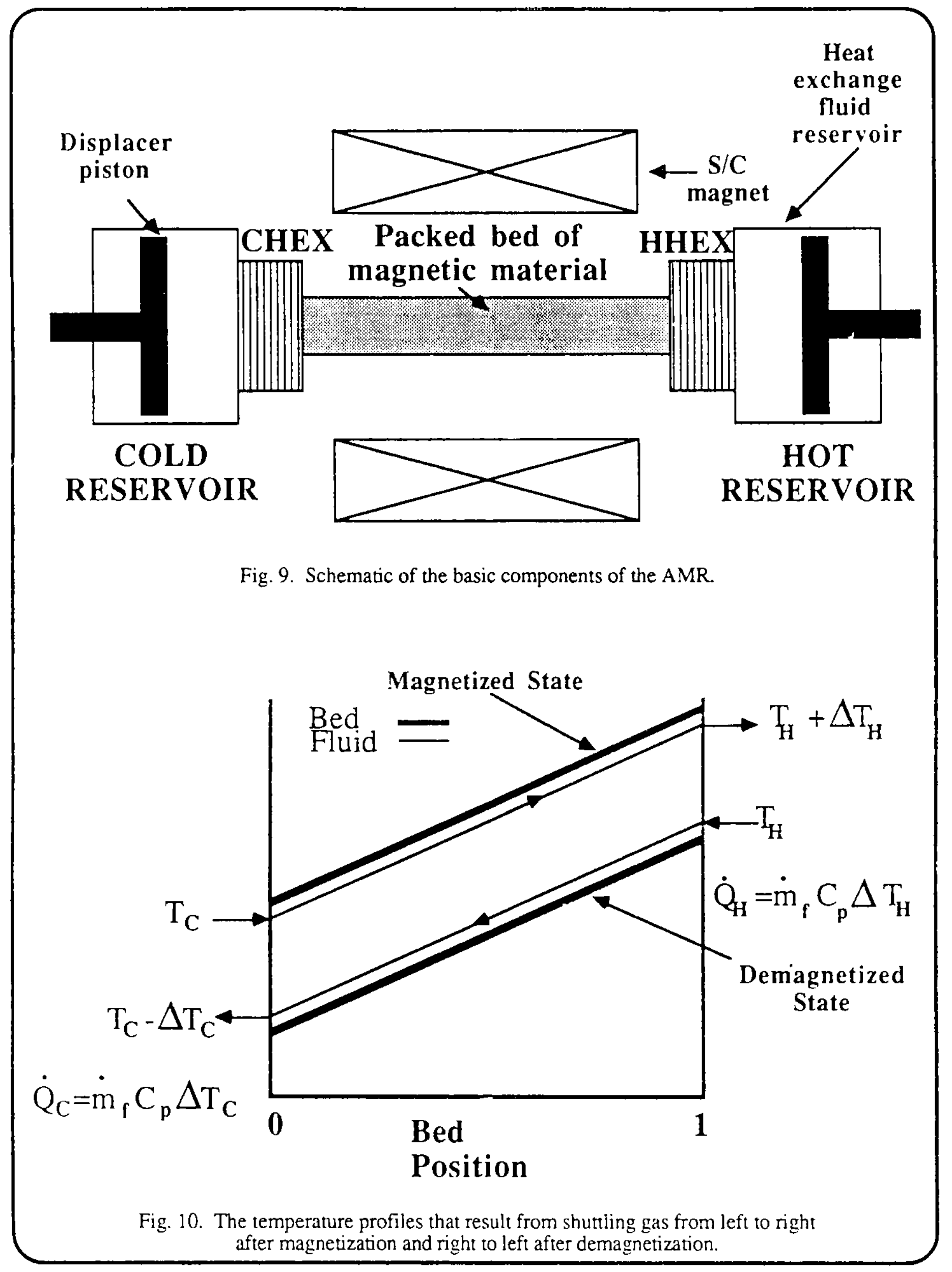


The AMR has an advantage over the standard recuperative or regenerative magnetic refrigerator because multiple materials can be used in the same device to achieve the ideal behavior. This is so because in the AMR, any given element of magnetic material executes a Brayton cycle over a limited temperature range. In a recuperative or regenerative magnetic refrigerator, by contrast, each element of magnetic material executes a single cycle over the entire temperature range of the refrigerator. In addition to this considerable advantage in achieving ideal behavior, the AMR has a comparatively simple flow control problem compared to the other recuperative or regenerative options. As a consequence, we have chosen the AMR as the device to use in the hydrogen liquefier.

\subsubsection{Description of the AMR Model}

The magnetic liquefier based on the AMR with liquid nitrogen precooling was modeled to compare with the conventional gas-cycle liquefiers. A schematic of the liquefier is shown in Fig. 11. The heat transfer fluid temperatures at the hot end of the AMR are a maximum of $9 \mathrm{~K}$ above $\mathrm{LN}_{2}$ normal boiling point, which naturally provides easy heat transfer. At the cold end of the AMR, the temperature of the GHe is at about $2 \mathrm{~K}$ below the normal point of $\mathrm{LH}_{2}(20 \mathrm{~K})$ for effective heat exchange. A reasonable effectiveness of $0.90-0.95$ is required for the external heat exchangers. The AMR magnetic stage is the core of the liquefier.

The AMR model used in this study is a modified version of that used in the study of MHPs for room-temperature applications.(35) The magnetic materials available for the bed in the $20 \mathrm{~K}$ to $77 \mathrm{~K}$ temperature range are not ductile. As a consequence, packed-particle beds were selected as opposed to parallel plates. The internal fluid is assumed to be gaseous helium as opposed to a liquid. Because the temperature range of interest varies by a factor of about four in absolute terms, variations in the fluid and bed properties become significant over the bed and have been considered. As in the previous study, it is assumed that the reduced period of the bed is zero. The reduced period is defined by

$$
\pi=h A P /\left(M_{m} C_{m}\right)
$$

where $\mathrm{P}$ is the time period of the flow in either direction; $h$ is the heat transfer coefficient of the bed; A its presented area; $M_{m}$ the total mass of the bed and $C_{m}$ the average heat capacity of the bed material. This assumption allows us to eliminate the time dependence in the problem. While it is possible to solve the more complete time dependent problem, computation time becomes prohibitively large for a study of this scope. While it may seem to be an unduly restrictive approximation to assume that the reduced period is zero, experience has shown that, as long as the ratio of reduced period to reduced length (defined below) is approximately 0.35 or less, the 
$\mathrm{GH}_{2} \mathrm{IN} \longrightarrow$

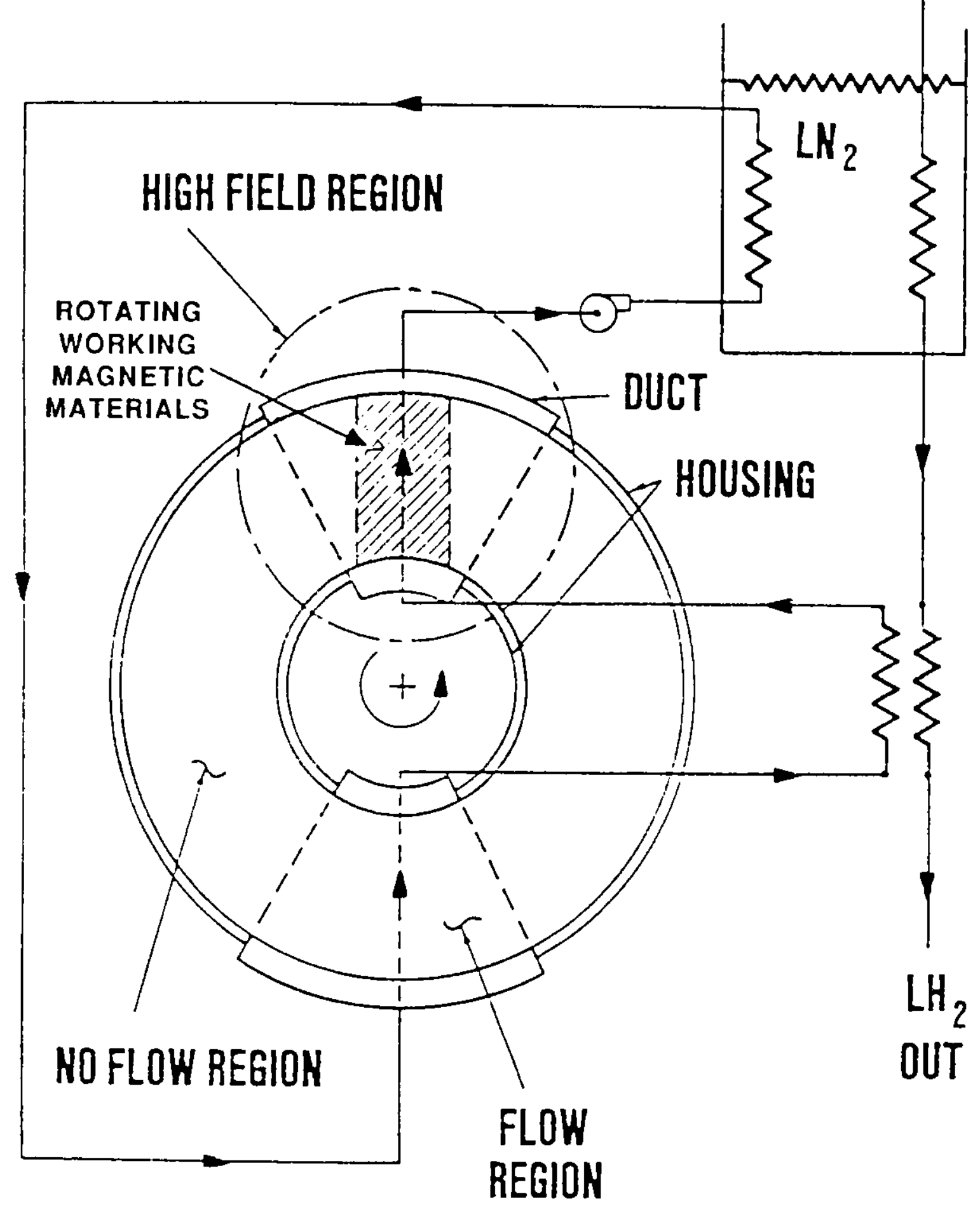

Fig. 11. MR using an active magnetic regenerative wheel. 
performance of the fully time dependent AMR model is essentially equivalent to the zero-reducedperiod result.

The reduced length is given by

$$
\Lambda=h A /\left(\dot{m}_{\mathrm{f}} \mathrm{C}_{\mathrm{p}}\right)
$$

where $\dot{m}_{f}$ is the fluid flow rate during the blow period and $C_{p}$ is the average heat capacity of the fluid.

In the computations, the variation with temperature of the thermal properties of the helium and the bed material are taken into account. The expression for the bed heat transfer coefficient is obtained from empirical data in the literature.(36) Axial thermal conduction is taken into account through use of an empirical expression. $(37,38)$ This is the conduction of heat through the particles and their contacts. Axial dispersion of fluid as it flows through the bed produces an additional source of thermal conduction which is accounted for through another empirical expression.(38)

Pressure drop is computed by a modified Ergun equation.(39) The work expended in pumping helium through the bed is added to the heat rejected at the hot end of the AMR. If the pump is placed before the gas enters the hot heat exchanger on its return to the bed, this assumption is accurate. It is also necessary for the gas to be ideal for this assumption to be accurate. Helium is quite close to an ideal gas in this temperature range. If the gas is not ideal, then there will be some $\mathrm{J}$ $T$ effect in going through the bed. In this case, there would be a slight additional cooling.

\subsubsection{AMR Performance Analysis}

In assessing the performance of an AMR as a relatively small-scale hydrogen liquefier, it is assumed that the magnetic properties of the packed-particle bed are ideal.(34) As previously' mentioned, because different materials can be used at different axial locations in the bed, it should be possible to come close to the ideal behavior in which the adiabatic temperature change with field which occurs in the bed is proportional to the absolute temperature. This means that for ideal behavior $\Delta \mathrm{T}_{\text {adiabatic }}=9 \mathrm{~K}$ at $80 \mathrm{~K}$, the hot end of the AMR bed, while at the cold $20 \mathrm{~K}$ end, $\Delta \mathrm{T}_{\text {adiabatic }}=2 \mathrm{~K}$.

The $\mathrm{E}_{\mathrm{x}} \mathrm{Gd}(1-\mathrm{x}) \mathrm{Al}_{2}$ series is a good starting point in attempting to approximate the ideal bed.(40) Depending on $\mathrm{x}$, the Curie point can vary over the entire range of interest, $20 \mathrm{~K}-80 \mathrm{~K}$. Mean field theory indicates that the adiabatic temperature change naturally decreases with temperature. If $\Delta \mathrm{T}_{\mathrm{adiab}}$ atic is too large at some temperature, another series material of different 
composition may be blended to provide the proper material properties. Experimental measurements will have to be made to validate and upgrade the mean field results.

The heat transfer fluid is assumed to be helium at $10 \mathrm{~atm}$ pressure. This reduces the pressure drop in the bed while maintaining the heat capacicy per unit volume of the helium in the bed smaller than that of the bed material (a bed porosity of $50 \%$ was assumed), even at the cold end. The pressure drops through the bed are typically in the several percent range. We therefore approximate the pressure at 10 atm when computing local properties of the helium in the bed over the cycle.

Figure 12 shows performance curves for an AMR of 5-cm length and a range of particle sizes, operating between $20 \mathrm{~K}$ and $77 \mathrm{~K}$. Similar calculations have been performed for $10 \mathrm{~cm}$ and 15 $\mathrm{cm}$ bed lengths but, for brevity, only the $5-\mathrm{cm}$ length is shown. As mentioned earlier, these results naturally include the temperature span for heat exchange, i.e., $18 \mathrm{~K}$ to $86 \mathrm{~K}$. Cooling power, efficiency and pressure drop are shown as a function of mass flow rate. As previously mentioned, when the ratio of reduced period to reduced length is less than or equal to about 0.35 , the zero reduced period results are very accurate. This condition can be written as follows:

$$
\mathrm{P}_{\max }=0.5(\mathrm{~L} / 10 \mathrm{~cm}) / \dot{\mathrm{m}}_{\mathrm{f}}
$$

where $P_{\max }$ is the maximum period of the AMR in seconds, $L$ is the length of the bed in $\mathrm{cm}$, and $\dot{\mathrm{m}}_{\mathrm{f}}$ is the fluid flow rate in grams per square centimeter second, as given in Fig. 12. If the AMR is operated above $P_{\max }$, the predicted performance progressively degrades.

Figure $12 \mathrm{a}$ illustrates that cooling power increases as particle size decreases. This is accounted for by the fact that the total contact area of the bed $A$ and the heat transfer coefficient $h$ of the bed increase as the paricle size decreases. The pressure drop also increases as the parcicie size decreases, however, which causes the efficiency to peak out.

For some particle sizes, the cooling power peaks as a function of mass flow rate. If mass flow rate were increased sufficiently, this would occur for all particle sizes. This is due to the fact that the reduced length decreases with increasing mass flow rate. Eventually the number of reduced lengths becomes small enough so that the AMR can not span the temperature range.

There are a number of differences between the methods of calculating the performance of refrigerators and liquefiers. A term frequently used is the coefficient of performance (COP). For 


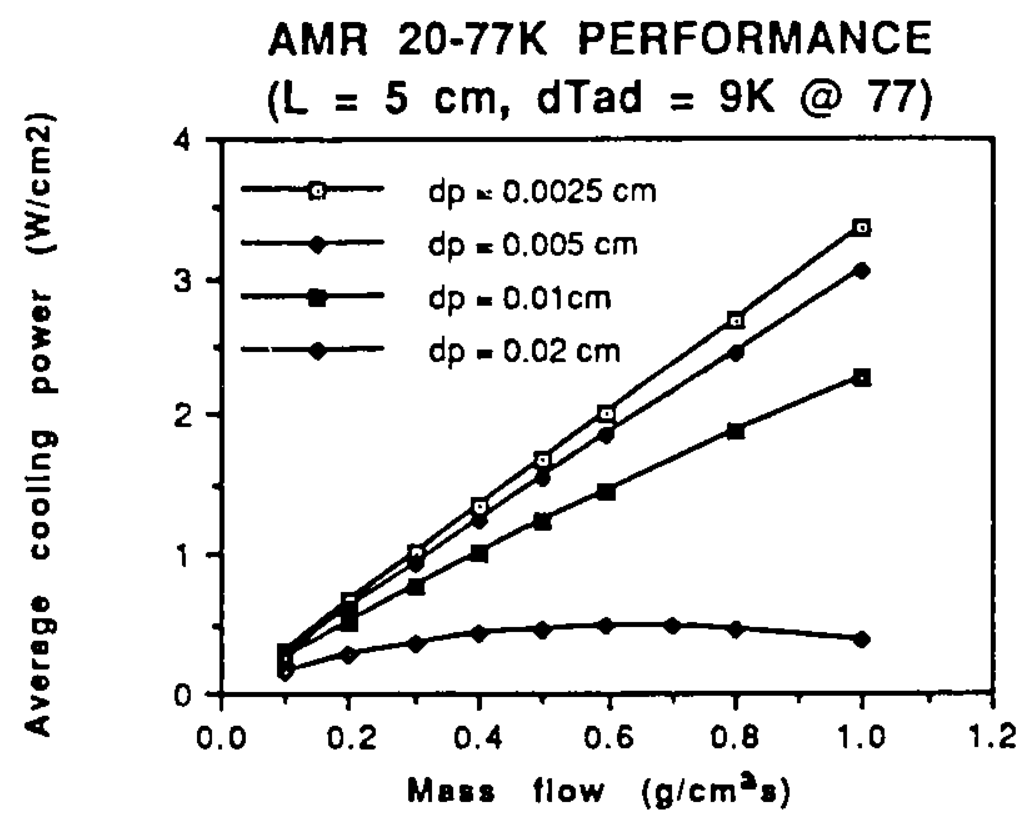

Fig. 12a. AMR 20 to $77 \mathrm{~K}$ refrigerator performance showing average cooling power versus mass flow rate for several values of particle size. Bed length is $5 \mathrm{~cm}$. Particle diameter is dp.

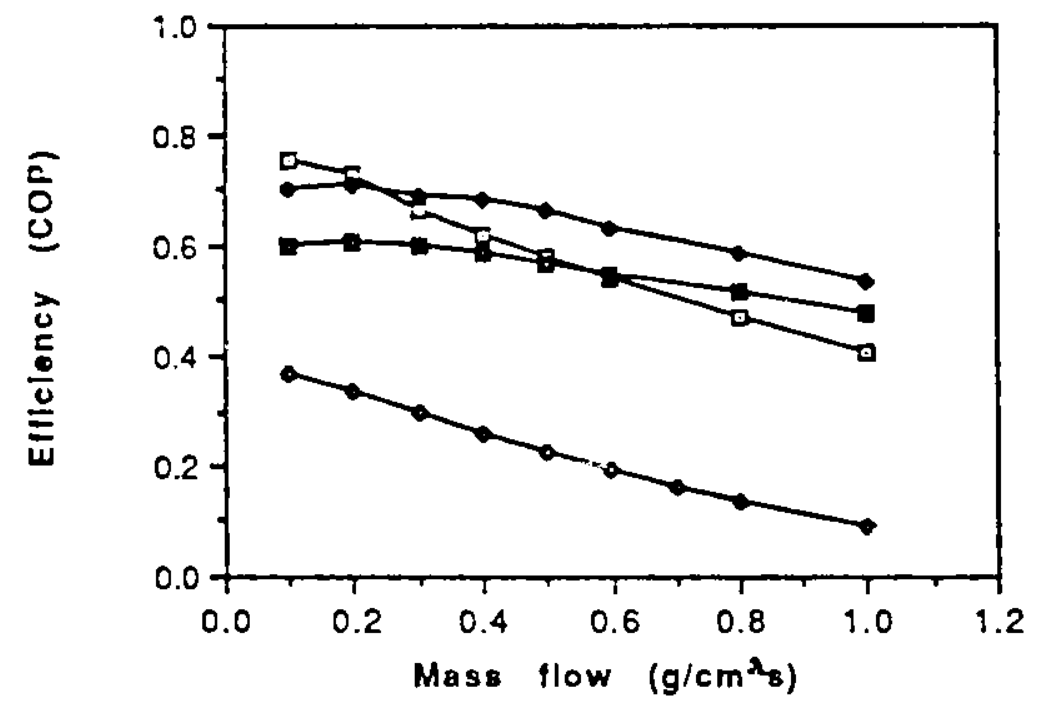

Fig. 12b. AMR 20 to $77 \mathrm{~K}$ refrigerator performance showing COP efficiency versus mass flow rate for several values of particle size. Bed length is $5 \mathrm{~cm}$. Particle diameter is $\mathrm{dp}$. 


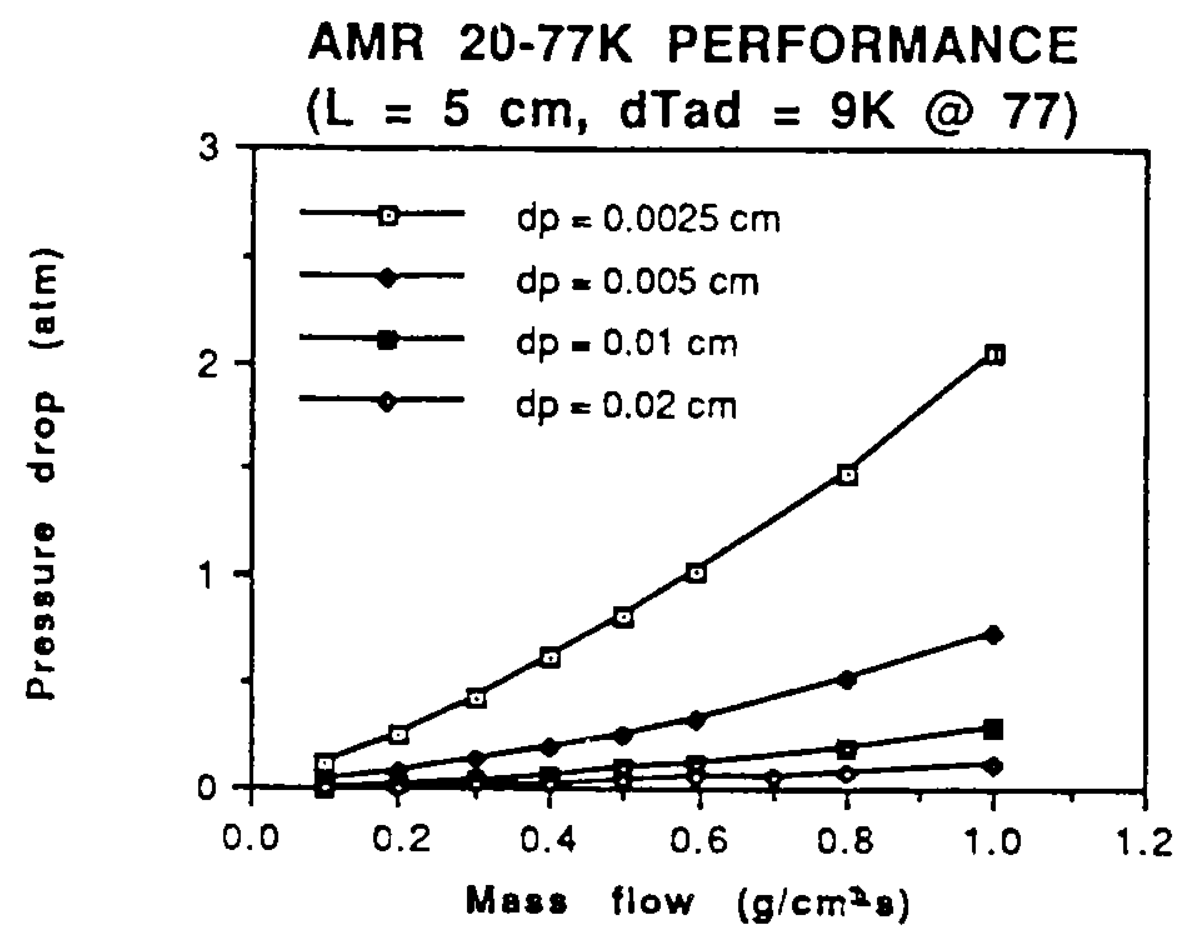

Fig. 12c. AMR 20 to $77 \mathrm{~K}$ refrigerator performance showing pressure drop versus mass flow rate for several values of particle size. Bed length is $5 \mathrm{~cm}$. Particle diameter is dp. 
refrigerators, the quantity of interest is the cooling power at the low temperature $\dot{Q}_{c}$, compared to the rate work is performed, $\dot{W}$. The actual COP is the ratio of these two quantities.

$$
\mathrm{COP}_{\mathrm{a}}=\dot{\mathrm{Q}}_{\mathrm{c}} / \dot{\mathrm{W}}
$$

The ideal cycle refrigeration cycle removing hear at $T_{C}$ and rejecting heat at $T_{H}$ is a Carnot cycle with no $\Delta \mathrm{T}$ required for heat exchange. Its $\mathrm{COP}$ is given by

$$
\left.\mathrm{COP}_{\mathrm{ideal}}=\mathrm{T}_{\mathrm{C}} / \mathrm{T}_{\mathrm{H}}-\mathrm{T}_{\mathrm{C}}\right)
$$

The efficiency of a refrigerator $\eta$, is then given by

$$
\eta_{\mathrm{COP}}=\mathrm{COP}_{\mathrm{a}} / \mathrm{COP}_{\text {ideal }}
$$

This is not the appropriate measure of liquefier efficiency since heat may be removed continuously between $\mathrm{T}_{\mathrm{C}}$ and $\mathrm{T}_{\mathrm{H}}$. In this case it is appropriate to consider the ideal or minimum work to liquefy a gas. The ideal work of liquefaction of a gas is the sum of the work to cool the gas isobarically to its boiling point, plus the work to liquefy it at constant temperature. Thus, for a gas of mass flow rate $\dot{m}$, starting at a high temperature $T_{H}$, with entropy $S$ and enthalpy $h$,

$$
\dot{\mathrm{W}}_{\mathrm{ideal}}=\dot{\mathrm{m}}\left(\Delta \mathrm{h}-\mathrm{T}_{\mathrm{h}} \Delta S\right) \text {. }
$$

A liquefaction efficiency can then be calculated once the actual work rate is known

$$
\eta_{\text {liq }}=\dot{w}_{\text {ideal }} \dot{w}_{a}
$$

For equilibrium hydrogen, $(41)$

$$
\begin{aligned}
& W_{\text {ideal }}(300 \mathrm{~K} \text { eq. to } 20 \mathrm{~K} \text { eq. })=14296 \mathrm{~J} / \mathrm{g} \\
& \mathrm{W}_{\text {ideal }}(77 \mathrm{~K} \text { eq. to } 20 \mathrm{~K} \text { eq. })=2066 \mathrm{~J} / \mathrm{g} \text {, }
\end{aligned}
$$

$\Delta \mathrm{H}(77 \mathrm{~K}$ eq. to $20 \mathrm{~K}$ eq. $)=1409 \mathrm{~J} / \mathrm{g}$.

Consider an AMR with a particle size of $0.01 \mathrm{~cm}$, a bed length of $5 \mathrm{~cm}$, and a mass flow rate of $0.5 \mathrm{~g} / \mathrm{cm}^{2} \mathrm{~s}$ (period $=1 \mathrm{~s}$ ). The total work predicted by the AMR model to make equilibrium 
liquid hydrogen from equilibrium hydrogen at $77 \mathrm{~K}$ is $6671 \mathrm{~J} / \mathrm{g}$, assuming a single-stage device in which all the sensible heat removal and O-P conversion is done at $20 \mathrm{~K}$. This results in a liquefaction efficiency of 0.31 , compared to the COP efficiency of the AMR of 0.57 .

A multi-stage liquefier which absorbs sensible heat and performs the O-P conversion at intermediate temperatures can have higher efficiency. Figure 13 illustrates one way of staging AMR refrigerators in this manner.

Figure 14 shows the results of a multi-stage analysis. Intermediate temperature points are distributed evenly in temperature between $20 \mathrm{~K}$ and $80 \mathrm{~K}$. For example, the three-stage device has intermediate temperature points at $40 \mathrm{~K}$ and $60 \mathrm{~K}$. Bed length is taken to be $5 \mathrm{~cm}$; particle diameter is $0.01 \mathrm{~cm}$, and flow rate is $0.5 \mathrm{~g} / \mathrm{cm}^{2} \mathrm{~s}$. Heat rejection and bed volume are computed assuming a 1 $v / d$ hydrogen liquefaction rate. If one prefers nitrogen boil-off rate, the conversion is

$$
\mathrm{N}_{2} \text { boil-off }(\mathrm{t} / \mathrm{d})=0.475 \times \text { Heat rejected }(\mathrm{kW})
$$

Assuming the heat of vaporization of $\mathrm{LN}_{2}$ is $200 \mathrm{~J} / \mathrm{g}$.(42)

Here it is assumed that only the heat of vaporization of the nitrogen is available to absorb the heat rejected at $77 \mathrm{~K}$. The sensible heat of the nitrogen vapor at $77 \mathrm{~K}$ is more than adequate to remove the sensible heat and O-P conversion energy of the hydrogen going from $300 \mathrm{~K}$ to $77 \mathrm{~K}$.

Liquefaction efficiency improves dramatically with number of stages. A three-stage device appears to be a good compromise between high efficiency and low comp'xity. A three-stage magnetic liquefier will be assumed throughout the remainder of the report.

The input power requirement for the liquefaction of nitrogen used in the boil-off can be used to arrive at an overall efficiency for the magnetic plant. From equation (9), the ideal work of liquefaction of nitrogen(42) is

$$
\mathrm{W}_{\text {ideal }}(300 \mathrm{~K} \text { to } 77 \mathrm{~K})=780 \mathrm{~J} / \mathrm{g}
$$

Assuming a large-scale $\mathrm{LN}_{2}$ plant has a liquefaction efficiency of $40 \%$, it is then possible to compute the total work input for the $\mathrm{LN}_{2}$ stage plus the magnetic and finally an overall efficiency for hydrogen liquefaction. It is instructive to follow a detailed example. From Fig. 14, a three-stage magnetic device is seen to reject $58.9 \mathrm{~kW}$ into $\mathrm{LN}_{2}$ and require $45 \mathrm{~kW}$ input power. Using the fact 


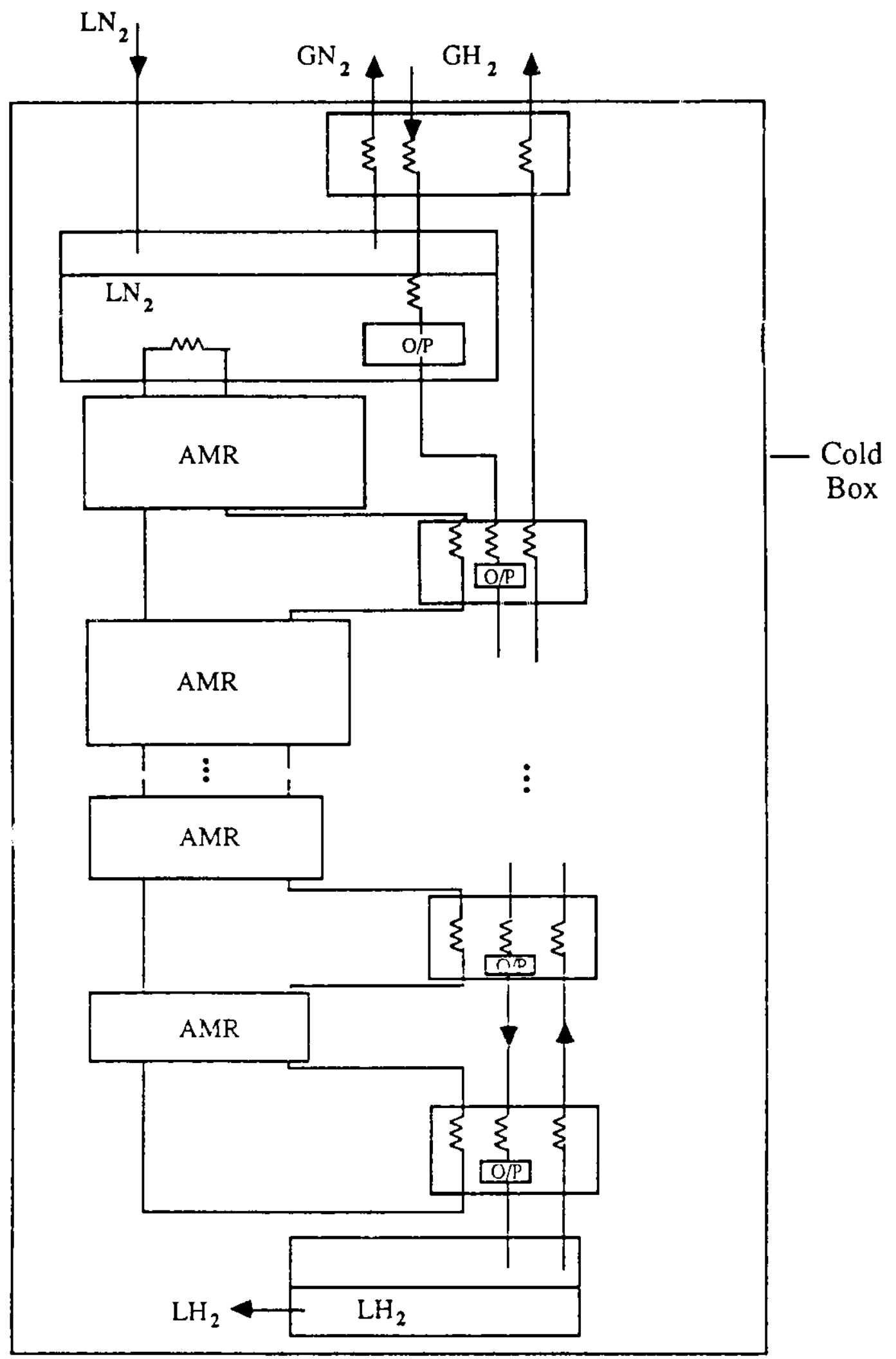

Fig. 13. Schematic of a multi-stage AMR hydrogen liquefier. 

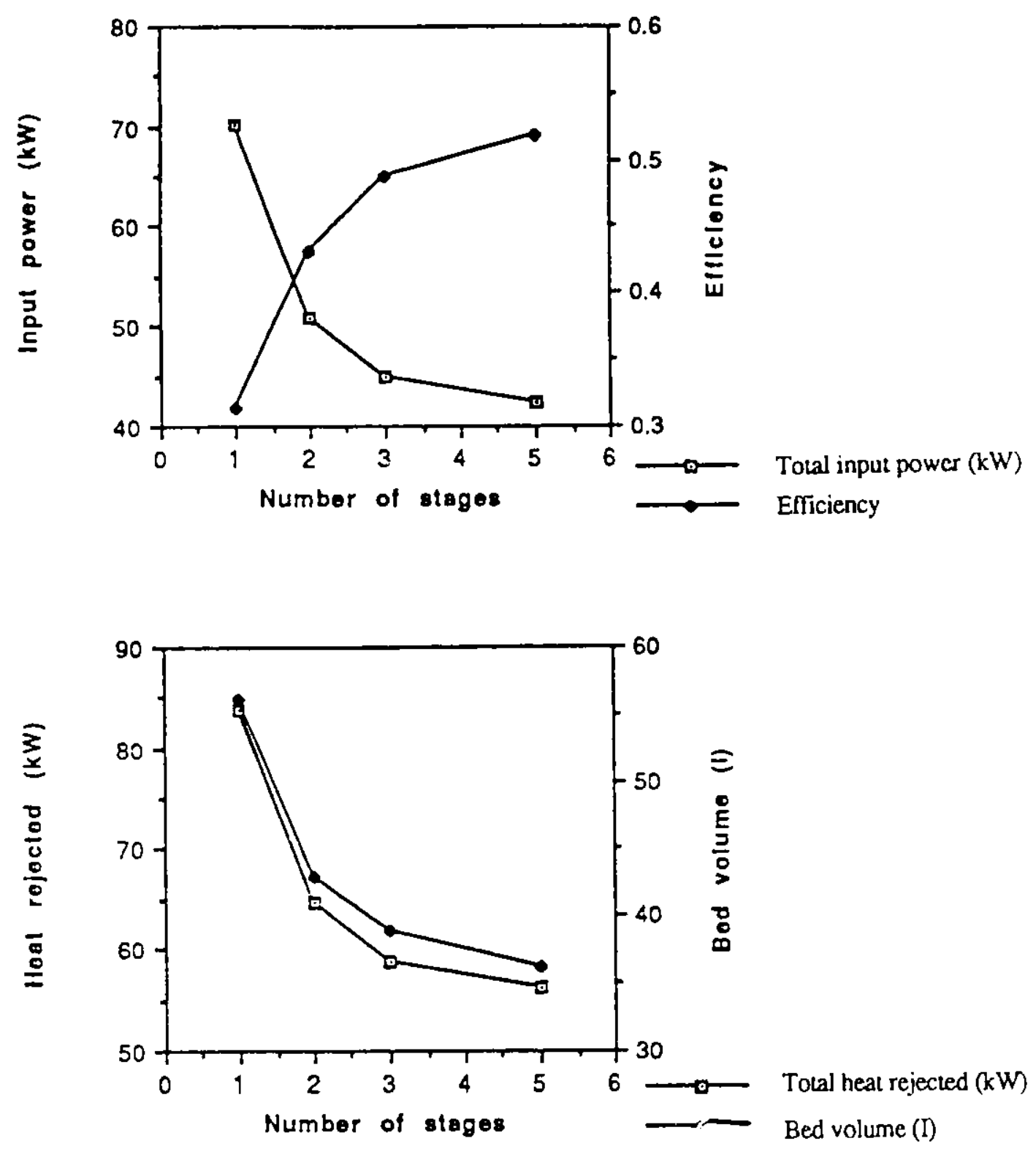

Fig. 14. Effects of the number of stages of the 20 to $77 \mathrm{~K}$ AMR hydrogen liquefier on performance. Liquefaction rate $=1 \mathrm{t} / \mathrm{d}$; particle size $=0.01 \mathrm{~cm}$; bed length $=5 \mathrm{~cm}$. 
that $1 \mathrm{t} / \mathrm{d}$ is equivalent to $10.5 \mathrm{~g} / \mathrm{s}$ and equation (11) for the ideal work to liquefy hydrogen from 77 $\mathrm{K}$ to $20 \mathrm{~K}$, it is clear that

$$
\eta_{\text {liq }}(77 \mathrm{~K} \text { to } 20 \mathrm{~K})=(2066 \mathrm{~J} / \mathrm{g})(10.5 \mathrm{~g} / \mathrm{s}) / 45 \mathrm{~kW}=48 \%
$$

The required liquid nitrogen production rate is (assuming heat of vaporization is $200 \mathrm{~J} / \mathrm{g}$ )

$$
\dot{\mathrm{m}}_{\mathrm{LN} 2}=(58.9 \mathrm{~kW}) /(200 \mathrm{~J} / \mathrm{g})=294.5 \mathrm{~g} / \mathrm{s}
$$

From equation (13), the power to the $\mathrm{LN}_{2}$ stage at $40 \%$ efficiency is

$$
\dot{\mathrm{W}}_{\mathrm{LN} 2}=(780 \mathrm{~J} / \mathrm{g})(294.5 \mathrm{~g} / \mathrm{s}) / 0.4=574.3 \mathrm{~kW}
$$

Thus, the total power input to the device is

$$
\dot{W} \text { total }=45 \mathrm{~kW}+574 \mathrm{~kW}=619 \mathrm{~kW}
$$

From equation (11), the overall liquefaction efficiency is

$$
\eta_{\text {liq }}(300 \mathrm{~K} \text { to } 20 \mathrm{~K})=(14296 \mathrm{~J} / \mathrm{g})(10.5 \mathrm{~g} / \mathrm{s}) / 619 \mathrm{~kW}=24 \%
$$

Note that if both the $\mathrm{LN}_{2}$ and magnetic devices were ideal, the best efficiency that could be achieved (because of the use of $\mathrm{LN}_{2}$ ) is

$$
\eta_{\text {liq } \max }=(150.1 \mathrm{~kW}) /(21.7 \mathrm{~kW}+229.7 \mathrm{~kW})=60 \%
$$

More generalized efficiency results are shown in Fig. 15. Three values for the efficiency of the nitrogen plant were used to bracket the $40 \%$ range and show the overall efficiency as a function of the efficiency of the $20 \mathrm{~K}$ to $77 \mathrm{~K}$ magnetic stage. If the efficiency of the magnetic stage is in the $50 \%$ range, as occurs in the three-stage AMR, the overall efficiency is in the low to mid $20 \%$ range. This efficiency is competitive with $5 \mathrm{vd}$ or greater conventional plants, $(30)$ and should exceed the efficiency of a conventional $1 \mathrm{t} / \mathrm{d}$ with a projected efficiency of $20 \%$.

Figure 16 shows the effect of period on performance of the AMR. Longer-period devices have slightly higher efficiency at the expense of a larger bed. 


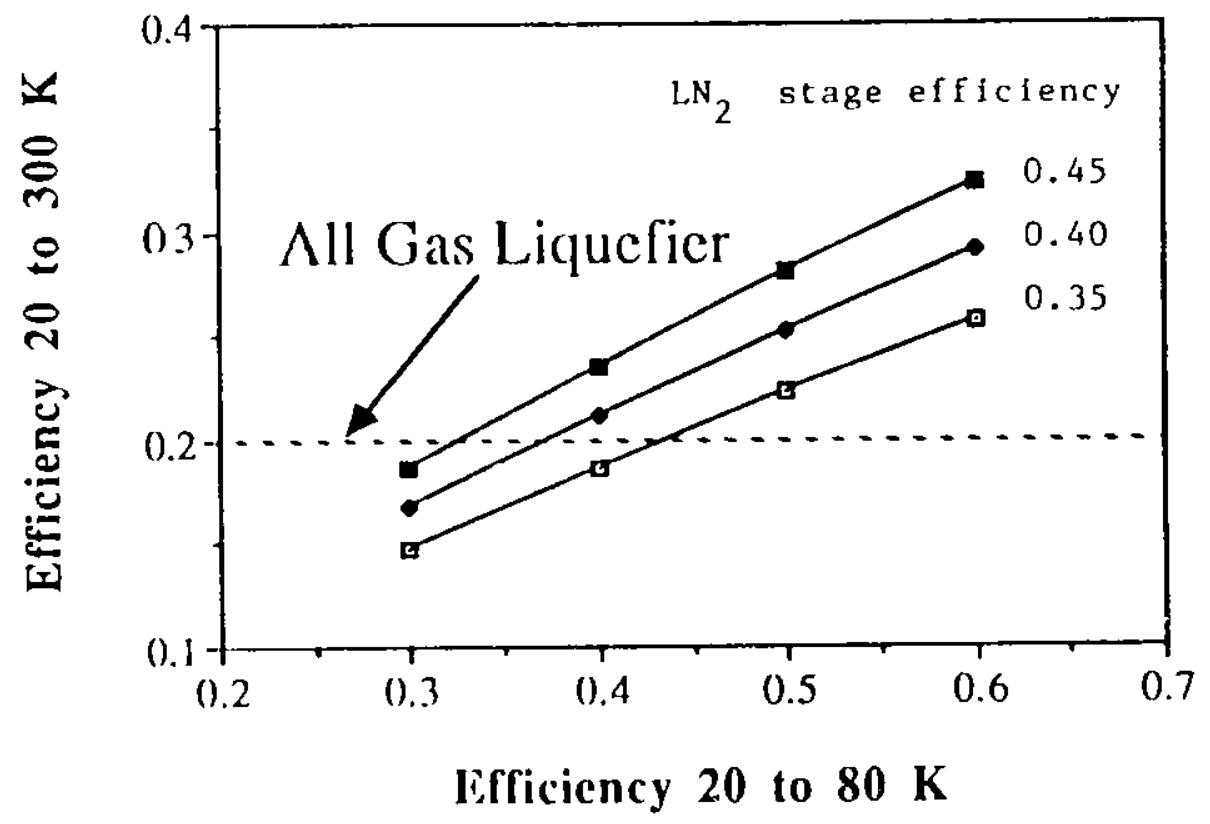

lig. 15. Overall efficicncy of the 20 to $300 \mathrm{~K}$ hydrogen liquefier as a function of the efficiency of the 20 to $80 \mathrm{~K}$ mangnetic lipuclier. 

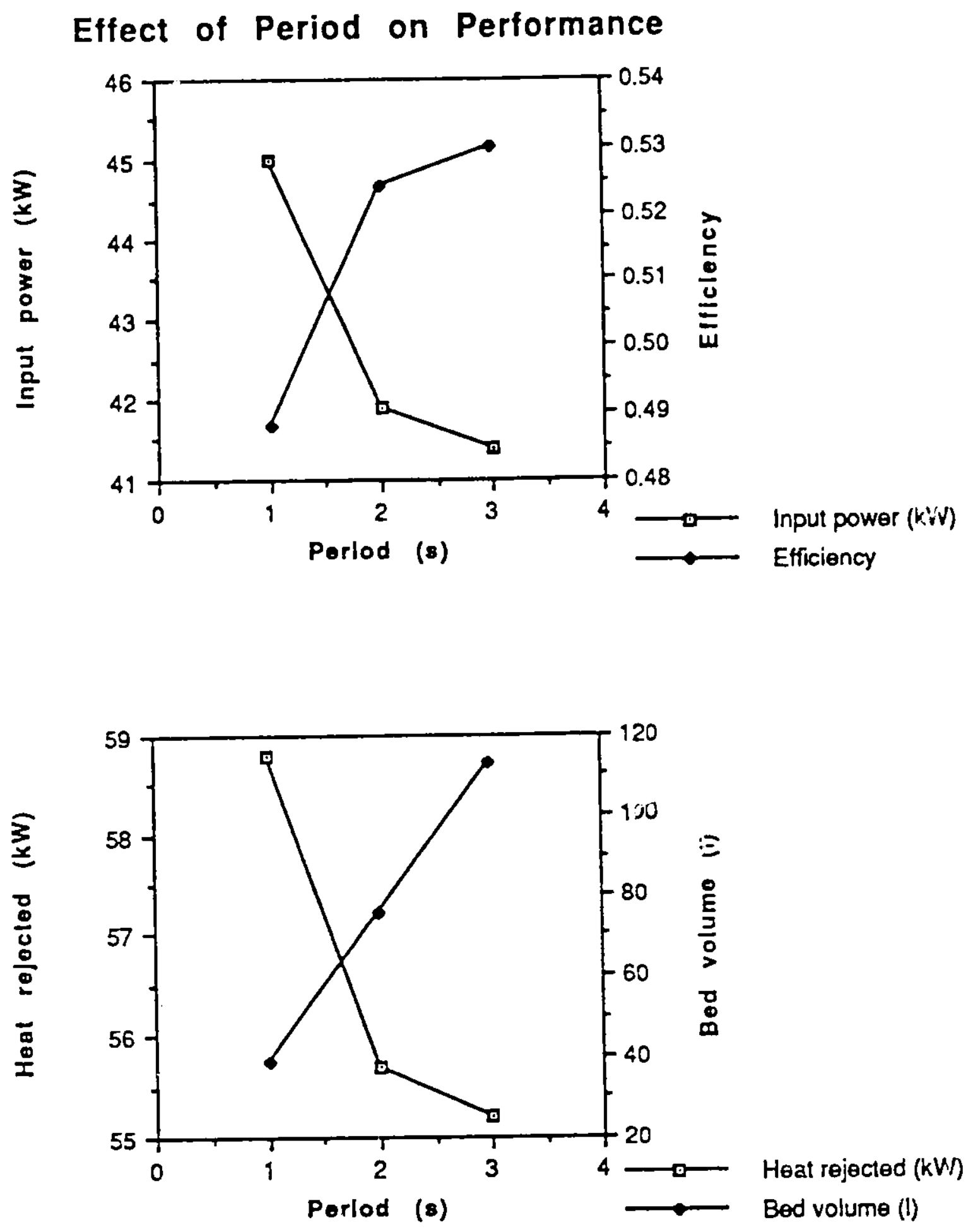

Fig. 16. Effect of $A M R$ period on performance. Liquefaction rate $=1 \mathrm{t} / \mathrm{d}$; particle size $=0.01 \mathrm{~cm}$; bed length $=5 \mathrm{~cm}$; three stage device. 
Figure 17 illustrates the effect of field change on performance, or more accurately, the effect of the adiabatic temperature change at $80 \mathrm{~K}$ of an ideal material on performance. As field increases, the adiabatic temperature change increases. Assuming $\operatorname{Er}_{\mathrm{x}} \mathrm{Gd}_{(1-\mathrm{x})} \mathrm{Al}_{2}$ with a Curie point of $80 \mathrm{~K}$ for the material at the hot end of the bed, the $9 \mathrm{~K}$ adiabatic temperature change corresponds to a field change of approximately 7 to 8 Tesla. An adiabatic temperature change of $5 \mathrm{~K}$ corresponds to a field change of about $5 \mathrm{~T}$. These results come from mean field theory. From the results of Fig. 17, a field change of $5 \mathrm{~T}$ would yield a device with too low an efficiency. A field change of 7 to 8 Tesla is necessary to produce a competitive device from the standpoint of efficiency.

\subsubsection{Scaling and Cost of AMR Liquefier}

Several different magnetic refrigerator scaling analyses were performed in this study. All involved a three-stage magnetic refrigerator for liquefying hydrogen, with $8 \mathrm{~T}$ superconducting magnets, external heat exchangers, O-P converters, and liquid nitrogen precooling of the incoming 1 $\mathrm{MPa}(1 \mathrm{~atm})$ hydrogen.

A rotary version of the AMR was chosen for the scaling and cost analyses but the reciprocating design should not be regarded as unsuitable. The rotary AMR naturally produces continuous cooling and uniform loads. It uses a wheel composed of many parallel particle beds in a radial direction. The magnet remains stationary and the magnetic material continuously enters and leaves the high-field region. Figure 11 illustrates the design. A high-field region is maintained by a toroidal magnet configuration. In the high-field region, an radially outward flow is produced by sliding seals on the inner and outer portion of the wheel. A housing surrounds the entire wheel so these seals are only for small $\Delta P$ flow control purposes, not sealing to the vacuum in the cold box. In the low-field region, similar manifolds and seals exist but the flow is radially inward.

In the first scaling analysis, the cost of a $1 \mathrm{t} / \mathrm{d}$ unit as a function of the wheel diameter was studied. The recurring cost breakdown for a $145-\mathrm{cm}$ mean diameter wheel is shown in Table VI below. The cost varied by less than $3 \%$ for wheel diameters varying from $80 \mathrm{~cm}$ to $200 \mathrm{~cm}$. In calculating the recurring costs, material and labor ( $\$ 10 / \mathrm{h} \mathrm{direct)}$ burden rates were assumed to be $100 \%$ and $200 \%$, respectively. The analysis was done hy taking each system component and estimating the cost to the manufacturer based on our experience and from calls to vendors. The source for each component is listed. Development costs have not been included. 


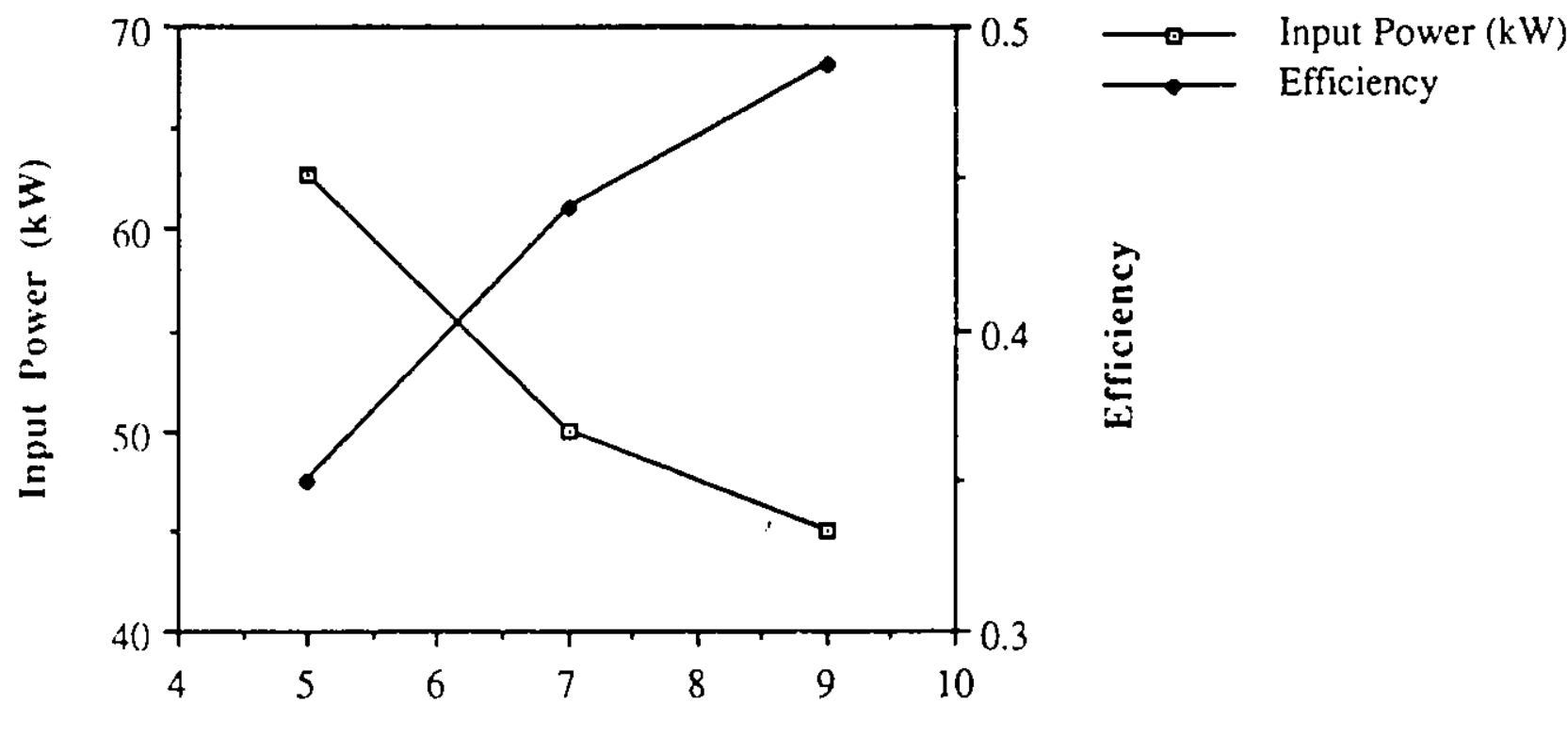

Field Strength (T)

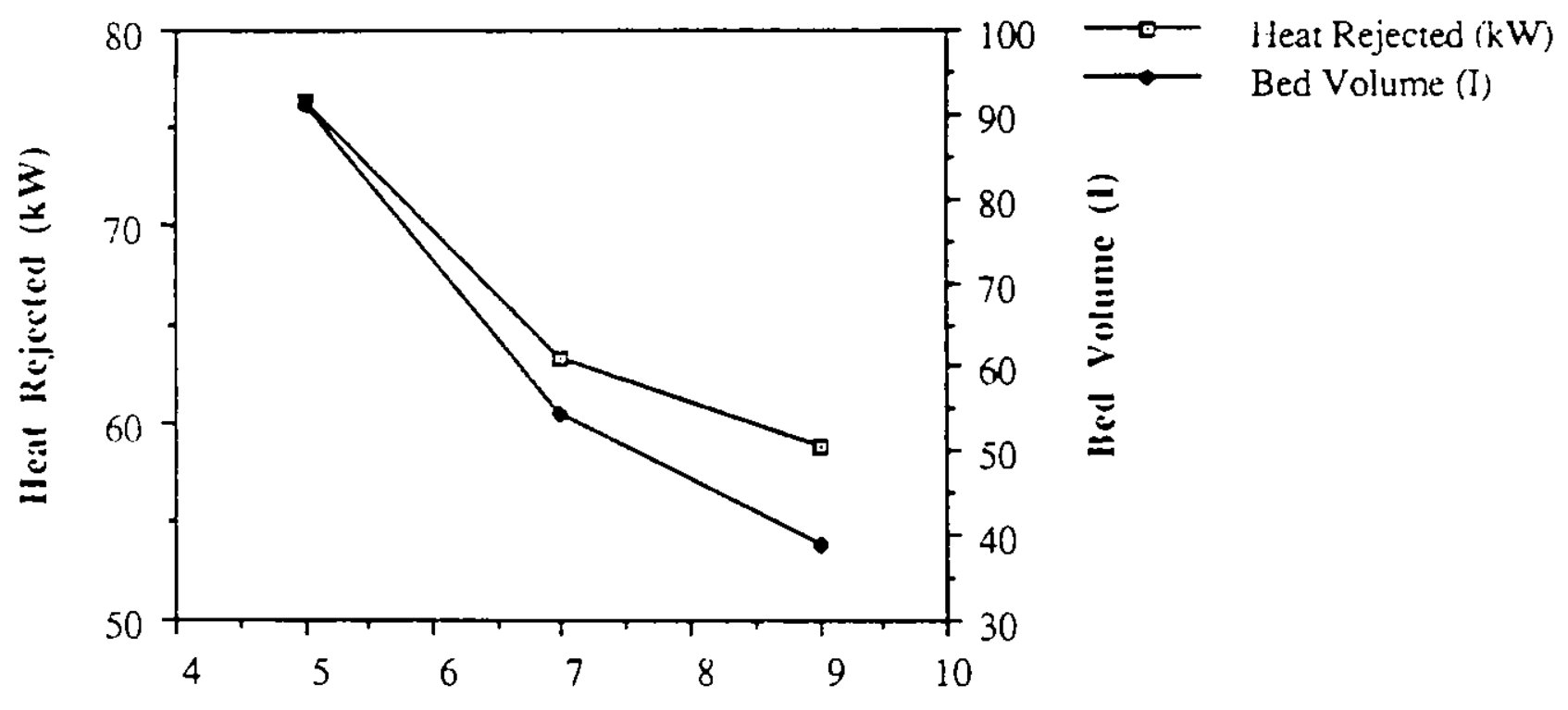

Field Strength $(\mathrm{T})$

Fig. 17. Effect of the field change on performance, expressed in terms of the adiabatic temperature change of the ideal magnetic material at $80 \mathrm{~K}$.

Liquefaction rate $=1 \mathrm{t} / \mathrm{d} ;$ particle size $=0.01 \mathrm{~cm}$; bed length $=5 \mathrm{~cm}$. 
TABLE VI.

COST BREAKDOWN OF 1 T/D HYDROGEN MAGNETIC LIQUEFIER

(Basis of cost estimate is in parentheses)

Component

$\operatorname{Cost}(\$)$

Magnet wire (Oxford Superconducting)

Magnet bobbin with HEX (ACA shop)

Magnet support structure (ACA shop)

Power supplies (engineering estimate)

Vacuum pumps (engineering estimate)

Wheel housing (American Fabrication)

Split wheel (AC Equipment Services)

Catalytic converters (Engineering estimate)

Seals (Engineering estimate)

Bearings

General support structure (ACA shop)

Drive system (shaft, motor, seals, gears) (Engineering estimate)

Heat exchangers (Engineering estimate)

Sensors, control system (ACA suppliers)

Dewars (NBP, LH 2 , LHe,cryostat)(ACA shop)

Misc. piping, valves, flanges

(Engineering estimate)

Assembly fixture for magnetic wheel

(AC Equipment Services)

Magnetic Material $(\$ 200 / \mathrm{kg})$

Materials Subtotal

Burden (100\%)

Labor, $7000 \mathrm{hrs}, \$ 10 / \mathrm{hr}$

Burden (200\%)

Recurring Cost

66,000

14,000

37,000

10,000

8,000

18,000

45,000

11,000

10,000

43,000

20,000

5,000

30,000

10,000

30,000

30,000

15,000

30,000

432,000

432,000

70,000

140,000

$\$ 1,074.000$

In another scaling analysis, the wheel diameter was evaluated as a function of the cooling power. Figure 18 shows the resuits for liquefaction rates varying from $200-1000 \mathrm{l} / \mathrm{h}(0.5-2 \mathrm{t} / \mathrm{d})$. This scaling is not intended to be a sophisticated, complete study of the optimum diameter wheel for each cooling power, but a preliminary study to indicate trends. Thus, the wheel diameter for a particular cooling power was chosen such that the superconducting magnet winding thickness was about $12 \%$ of the mean radius of the wheel. Under these conditions, there should be adequate spacing for the individual solenoidal coils in the center portion of the wheel, as seen in Fig. 11. Figure 18 indicates that the magnetic liquefier is extremely compact; a $2 \mathrm{t} / \mathrm{d}$ unit is only about six feet in diameter.

Using the wheel diameters found above, the burdened, recurring cost of the complete liquefier was determined as a function of the cooling power. The results are shown in Fig. 19. In 


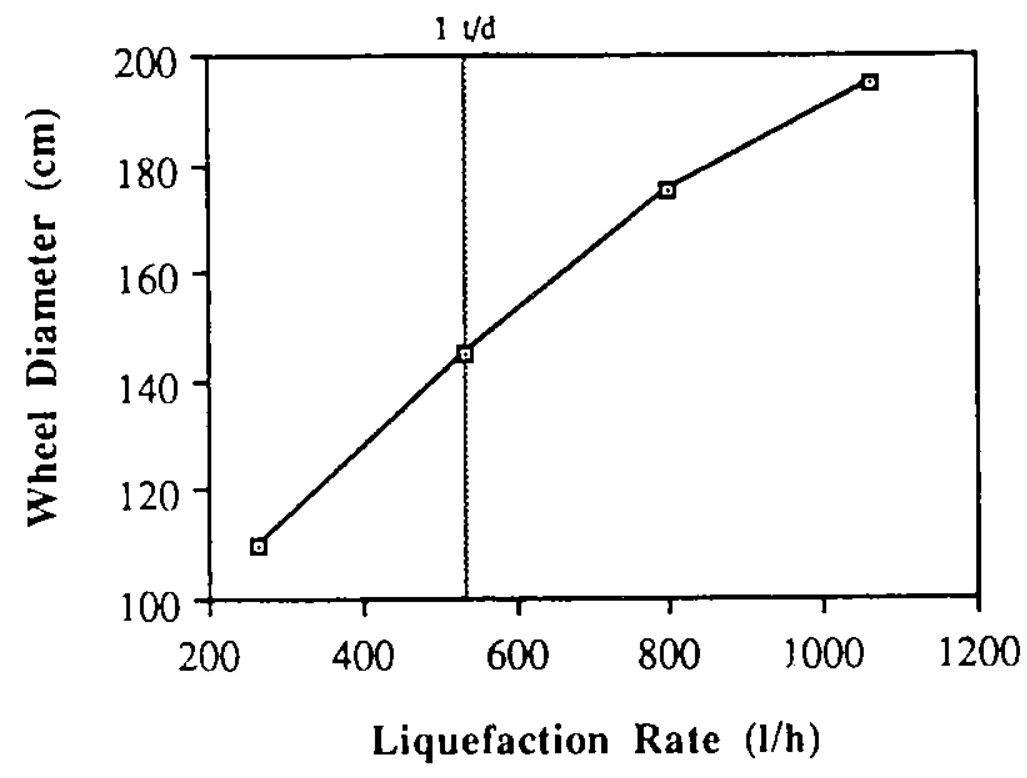

Fig. 18. Mean wheel diameter versus liquefaction rate of magnetic hydrogen liquefier.

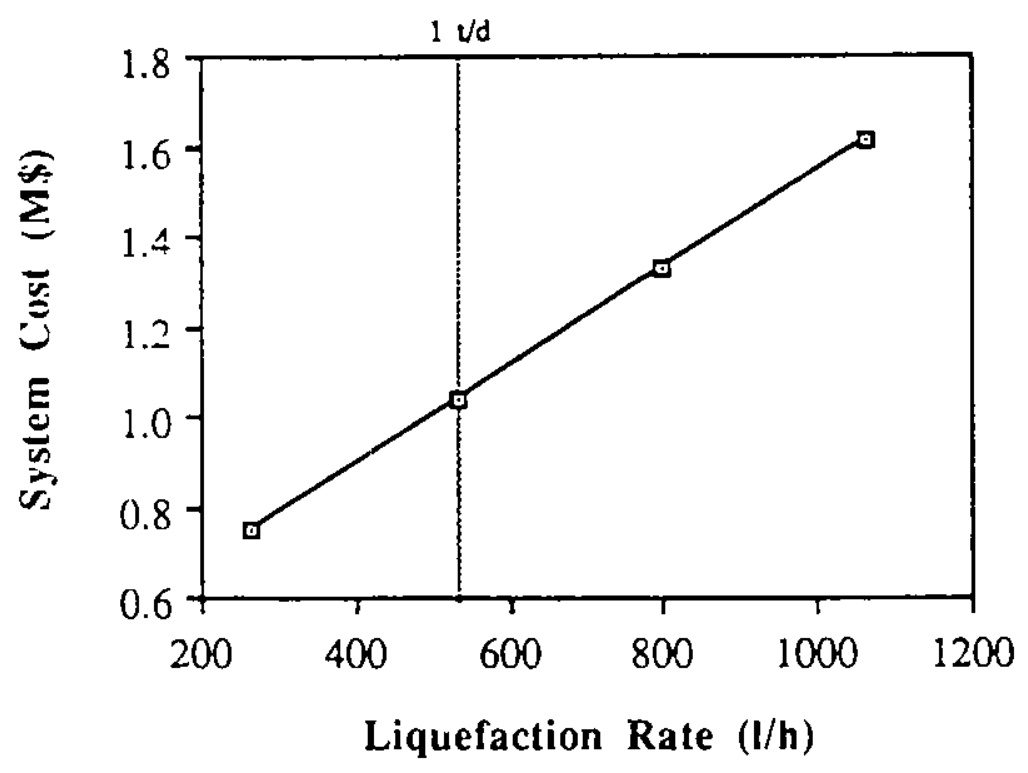

Fig. 19. Complete liquefier system cost as a function of liquefaction rate. 
this relatively simple analysis, the cost of the system appears linearly dependent on cooling power over the range $0.5-2 \mathrm{t} / \mathrm{d}$, such that

$$
\text { Cost }=0.001 \times(\text { Liq. Rate, } l / \mathrm{h})+0.54
$$

where cost is in millions of dollars and the liquefaction rate is in liters per hour. For example, the cost of a $1 \mathrm{t} / \mathrm{d}$ or $533 \mathrm{l} / \mathrm{h}$ system is $\$ 1.07 \mathrm{M}$. This capital cost is much less than the projected cost for a conventional gas cycle device. The smallest commercial hydrogen liquefier is a $5 \mathrm{t} / \mathrm{d}$ device whose capital cost is about $\$ 12.5 \mathrm{M}$. If this cost is linearly extrapolated to a $1 \mathrm{t} / \mathrm{d}$ unit, it would cost $\$ 2.5 \mathrm{M}$ or more than twice the $1 \mathrm{v} / \mathrm{d}$ magnetic liquefier. A summary listing of the characteristics of a $1 \mathrm{Vd}$ magnetic hydrogen liquefier is shown in Table VII.

TABLE VII.

CHARACTERISTICS OF A $533 \mathrm{l} / \mathrm{h}$ (1 $\mathrm{t} / \mathrm{d})$ MAGNETIC HYDROGEN LIQUEFIER

$\begin{array}{ll}\text { Parameter Value } & \end{array}$

$\mathrm{LH}_{2}$ Production Rate

Stages

Nominal Cold End Temperature

Stage 1

Stage 2

Stage 3

High-Temperature Heat Sink

$\mathrm{LN}_{2}$ Boil-off Rate

Mean Wheel Diameter

Wheel Speed

Field Strength

Magnetic Material

Amount of Magnetic Material

Input Power (drive motor)

Efficiency $80 \mathrm{~K}-20 \mathrm{~K}$

Overall Efficiency $300 \mathrm{~K}-20 \mathrm{~K}$

(assuming $\mathrm{LN}_{2}$ produced at $40 \%$ )

Estimated System Cost

$533 \mathrm{l} / \mathrm{h}(1 \mathrm{v} / \mathrm{d})$
3
$60 \mathrm{~K}$
$40 \mathrm{~K}$
$20 \mathrm{~K}$
$\mathrm{LN} \mathrm{i}_{2}$
$1310 \mathrm{l} / \mathrm{h}(27.9 \mathrm{t} / \mathrm{d})$
$145 \mathrm{~cm}$
$60 \mathrm{rpm}$
$8 \mathrm{~T}$
$\mathrm{Er}_{\mathrm{x}} \mathrm{Gd}_{1-\mathrm{x}} \mathrm{Al}_{2}$
$152 \mathrm{~kg}$
$45 \mathrm{~kW}$
$48 \%$
$24 \%$
$\$ 1,074,000$

\section{UPDATE OF ROOM-TEMPERATURE MHP REPORT}

Astronautics Corporation of America completed a study entitled "Assessment of the Impact of High Temperature Superconductors on Room Temperature Magnetic Heat Pumps/Refrigerators" for ANL that was sponsored jointly by DOE's Office of Energy Conservation and Utilization Technology (ECUT) and EPRI in July 1988 (Contract no. 81032401). This study took a "first look" at the potential impact of high-temperature superconductors (HTSCs) on magnetic heat pumps 
(MHPs). In particular, the study focused on both a heat pump absorbing energy from $350 \mathrm{~K}$ water and delivering $500 \mathrm{~kW}$ to produce $389 \mathrm{~K}$ water, and an industrial refrigeration unit (supermarket freezer) removing $50 \mathrm{~kW}$ from $255 \mathrm{~K}$ air and exhausting to $308 \mathrm{~K}$ air. Recuperative and regenerative magnetic devices were analyzed.

Some of the conclusions from the room-temperature MHP study are reiterated below.

- Reliability is probably the most important criteria for selection of refrigerator or heat pump equipment, although cost is a close second in importance.

- A 50-kW magnetic heat pump and refrigerator has been conceptually analyzed and modeled to show performance comparable to, or better than, conventional vapor compression devices.

- The active magnetic regenerator appears to have several advantages compared to the magnetic recuperative design.

- The magnetic regenerator achieves high performance, i.e., large heat flux per $\mathrm{kg}$, by operating at higher frequency than earlier magnetic designs. (The frequency is well below that of comparable regenerative gas-cycle refrigerators.)

- The capitai and operating costs of the 50-kW magnetic devices has been estimated. The capital costs appear larger than those of vapor-compression devices but the operating costs are lower so an overall cost advantage appears after a few years.

- The costs of the magnetic units are a weaker function of size than for the vaporcompression devices because similar magnets can be used for a variety of sizes.

- The magnetic heat pumps appear to be much more tolerable of variation in hot and cold temperatures, which is generally not true for vapor compression devices.

- Magnetic units do not use chlorofluorocarbons.

One of the objectives of the present study is to update the ECUT/EPRI report based on the results of this work. Although both studies involve MHP technology and both concentrate on rotary, 
regenerator devices, there are significant differences which minimize the analysis overlap. The supermarket refrigerator used:

- liquid (water plus ethanol) for heat transfer to the magnetic material (implies very high heat transfer);

- parallel plates of magnetic material, gadolinium (implies ductile or malleable material);

- porosity of $10 \%$ (high heat transfer); and

- the external medium to which heat is absorbed and rejecied is a gas.

The hydrogen liquefier uses:

- helium gas for heat transfer to the magnetic material (relatively poor heat transfer);

- packed particle bed of magnetic material, $\mathrm{Er}_{x} \mathrm{Gd}_{(1-\mathrm{x})} \mathrm{Al}_{2}$ (brittle material);

- $\quad$ porosity of $50 \%$ (about the lowest easily obtained porosity);

- the external medium to which heat is absorbed and rejected is mainly liquid.

Thus, the only practical area of overlap is in the costing analysis. The costing shown in Table VII is more extensive than in the previous study. In many cases, costs have been verified by outside vendors. The same analysis was applied to the $50-\mathrm{kW}$ supermarket refrigerator. The total materials cost is about 15\% higher, but the estimated retail cost is almost twice that obtained previously ( $\$ 55 \mathrm{~K}$ now versus $\$ 26 \mathrm{~K}$ before). The new detailed cost breakdown with burdening broken out is in Table VIII. Note that this breakout does not contain a magnet power supply or vacuum pump because it was assumed that these would be used infrequently and therefore, supplied by a servicing contract. 
TABLE VIII.

COST BREAKDOWN OF A $50 \mathrm{~kW}$ SUPERMARKET FREEZER

(Basis of cost estimate is in parenthesis)

Component

Magnet wire (Oxford Superconducting)

Magnet bobbin with HEX (ACA shop)

Magnet support structure (ACA shop)

Wheel housing (American Fabrication)

Split wheel (AC Equipment Services)

Adiabatic material(Engineering estimate)

Seals (Engineering estimate)

Bearings

General support structure (ACA shop)

Drive system (shaft, motor, seals, gears)

(Engineering estimate)

Manifolds (Engineering estimate)

Sensors, control system (ACA suppliers)

Dewars (NBP,LH 2, LHe,cryostat)(ACA shop)

Misc. piping, valves, flanges

(Engineering estimate)

Magnetic Material $(\$ 100 / \mathrm{kg})$

Materiais Subtotal

Burden (100\%)

Labor, $800 \mathrm{hrs}, \$ 10 / \mathrm{hr}$

Burden (200\%)

Recurring Cast
Cost (\$)

3,600

1,200

400

1,400

500

1,200

700

200

500

500

500

1,000

2,000

100

1,500

15,300

15,300

8,000

16,000

$\$ 54.600$

A number of factors contribute to this difference in retail costs. The previous analysis was simplistic and brief. Retail costs were assumed to be twice the cost to the manufacturer. Consultanis indicated that a factor of three would not be unreasonable. Thus, the $\$ 55,000$ re:ail cost is probably now representative of the first cost of a $50 \mathrm{~kW}$ magnetic supermarket freezer. This cost should still be interpreted cautiously. A preliminary design of any real device is required to provide vendors with drawings before a more accurate costing can be performed.

\section{MAGNETIC REFRIGERATOR APPLICATIONS UP TO $300 \mathrm{~K}$}

One of the objectives of this study is to consider the application of a magnetic refrigerator above $77 \mathrm{~K}$. Although the liquefaction of numerous gases other than hydrogen could have been considered, the scope of the project was limited by replacing the $\mathrm{LN}_{2}$ stage of the hydrogen liquefier with a magnetic refrigerator. Table IX gives the specifications and performance of an AMR operating between 77 and $300 \mathrm{~K}$, computed using a zero-reduced-period AMR model. It is assumed 
that the magnetic material is ideal over the temperature range, and the dimensions and operating parameters have not been optimized.

TABLE IX. AMR PERFORMANCE SPECIFICATIONS FOR $300 \mathrm{~K}$ TO $80 \mathrm{~K}$ OPERATION

Dimensions \& Operating Parameters:

Performance:

- Length $=30 \mathrm{~cm}$

- Cross section $=150 \mathrm{~cm}$

- Particle size $=0.03 \mathrm{~cm}$

- Porosity $=0.5$

- Internal pressure $=50 \mathrm{~atm}$

- Pressure drop $=0.3 \mathrm{~atm}$

- Mass flow=30 g/s ( 4 l/s@ $300 \mathrm{~K})$

- Field change $=8 \mathrm{~T}$
- $\quad$ Temperature range $=77 \mathrm{~K}$ to $300 \mathrm{~K}$

- Cooling power $=2.57 \mathrm{~W} / \mathrm{cm}^{2}$

- Heat rejected $=15.11 \mathrm{~W} / \mathrm{cm}^{2}$

- Pumping loss $=1.07 \mathrm{~W} / \mathrm{cm}^{2}$

- Conduction loss $=0.2 \mathrm{~W} / \mathrm{cm}^{2}$

- Axial dispersion loss $=35 \mathrm{~W}$

- Liquefaction eff. $=0.45$

As can be seen from the table, high efficiency is possible. Efficiency better than a large gascycle unit is possible with a small magnetic unit. It may be appropriate to consider whether there are similar market niches in this higher temperature range. Using the $300 \mathrm{~K}$ to $77 \mathrm{~K}$ magnetic stage to replace the $\mathrm{LN}_{2}$ in the hydrogen liquefaction results in an improved overall liquefaction efficiency. Coupled with $50 \%$ efficient $77 \mathrm{~K}$ to $20 \mathrm{~K}$ device, the $\mathrm{m}-\mathrm{ll}$ hydrogen liquefaction efficiency is $28 \%$.

There are more problems developing an AMR in the 77 to $300 \mathrm{~K}$ range compared to the 20 to $77 \mathrm{~K}$ range. There are good candidate materials to fabricate an 'ideal bed' for the lower temperanure device. For the higher-temperarure device this is not the case, although active materials over the entire range exist. Containment of the high-pressure helium is a potential problem. Going to lon'er pressure will reduce efficiency by increasing the loss due to pumping work. It may be possible to use liquids in the higher-temperature range above about $150 \mathrm{~K}$. This would reduce pumping work without high pressure. A low-porosity, parallel-plate bed configuration will probably be necessary in that case. Clearly, in this operating temperature range of $77 \mathrm{~K}$ to $300 \mathrm{~K}$, the future use of hightemperature superconducting magnets would increase the practicality of the device.

\section{SUMMARY/CONCLUSIONS}

Several significant conclusions can be drawn as a result of this study. They are summarized below. 
- Market analysis indicates that there is a need for a one ton per day $(1 \mathrm{t} / \mathrm{d})$ magnetic hydrogen liquefier.

* The magnetic hydrogen liquefier offers reduced capital and operating costs over (projected) conventional $1 \mathrm{t} / \mathrm{d}$ liquefiers.

* $\quad$ Reduced costs will probably lead to more extensive distribution of $\mathrm{LH}_{2}$ production facilities.

* More extensive distribution of facilities will reduce $\mathrm{LH}_{2}$ transportation distance/costs.

* The result is lower $\mathrm{LH}_{2}$ cost to consumer and $\mathrm{LH}_{2}$ market growth.

- A three-stage active magnetic regenerative refrigerator (AMR) rejecting heat to a $\mathrm{LN}_{2}$ bath provides a compact, efficient, and relatively inexpensive method of liquefying hydrogen.

- A rotary AMR design with a series of solenoids forming a portion of a toroid penetrated by a wheel sectioned into parallel packed-particle beds of magnetic material is a reasonable concept for the liquefier.

- The mean wheel diameter of a $1 \mathrm{t} / \mathrm{d}$ magnetic hydrogen iiquefier could be less than $1.5 \mathrm{~m}$. The device is very compact.

- The capital cost of a $1 \mathrm{t} / \mathrm{d}$ magnetic liquefier is estimated at $\$ 1.07 \mathrm{M}$; a comparable conventional liquefier is projected to cost $\$ 2.5 \mathrm{M}$.

- The predicted overall efficiency (which is a direct reflection of the operating cost) of the magnetic liquefier is $2.1 \%$. The efficiency of a comparable conventional iquefier is projected to be about $20 \%$.

- An all-magnetic hydrogen liquefier is predicted to have a $28 \%$ overall liquefaction efficiency. A more detailed, multi-stage analysis of the $300 \mathrm{~K}$ to $80 \mathrm{~K}$ staging may further increase this efficiency.

- Applying the results of this study to the earlier ECUT/EPRI study on a MHP for a supermarket freezer indicates that the lowest cost of a $50-\mathrm{kW}$ magnetic freezer with conventional superconducting magnets $(\$ 55 \mathrm{k})$ is not capital-cost competitive with the highly developed vapor-compression freezer $(\$ 9 \mathrm{k})$. 
Table $\mathrm{X}$ presents a summary and comparison of the various liquefaction options.

\section{RECOMMENDATIONS}

The small-scale (0.5-2 $\mathrm{t} / \mathrm{d})$ liquefaction of hydrogen appears to be an ideal market in which to introduce the new technology of MHPs. Compared to conventional gas compression refrigerators, MHPs promise to be much more compact, allowing easy siting arrangements. MHPs promise to be more efficient, providing reduced operating costs. The capital cost of MHPs should be less than half that of conventional devices.

Several recommendations can be made for immediate future work leading toward industrial magnetic heat pumps, in particular, a magnetic hydrogen liquefier. The details of the research and development program and schedule would depend on DOE goals and funding commitments. 
TABLE X.

EFFICIENCY COMPARISON OF I 'TON PLIR DAY ALL-GAS HYDROGEN LIQUEFIERS TO MAGNETIC LIQUEFIER COMBINATIONS

\begin{tabular}{|c|c|c|c|}
\hline & $\begin{array}{l}\text { Temperature Range } \\
\text { \& Technology }\end{array}$ & $\begin{array}{l}\text { Overall } \\
\text { Liquefaction } \eta\end{array}$ & $\frac{\text { Relative Energy }}{\text { Unit Mass of } \mathrm{LH}_{2}}$ \\
\hline $\begin{array}{l}1 \mathrm{t} / \mathrm{d} \text { all gas } \\
\text { hydrogen liquefier }\end{array}$ & $\begin{array}{c}(300) \mathrm{K}-20 \mathrm{~K} \text { all gas }) \\
\mathrm{I}-9.20\end{array}$ & $\eta=0.20^{*}$ & 1.0 \\
\hline $\begin{array}{l}27 \mathrm{t} / \mathrm{d} \mathrm{LN} \mathrm{L}_{2} \\
\text { plant on-site } \\
+\mathrm{AMR}\end{array}$ & $\begin{array}{c}(300 \mathrm{~K}-77 \mathrm{~K} \text { (ga.i) }+(77 \mathrm{~K}-20 \mathrm{~K} \text { AMR }) \\
\eta=0.25 \quad \eta=0.49\end{array}$ & $\eta=0.16$ & 1.25 \\
\hline $\begin{array}{l}27 \mathrm{t} / \mathrm{d} \text { delivered } \\
\text { from a large } L N_{2} \\
\text { plant }+A M R\end{array}$ & $\begin{array}{c}\left(300 \mathrm{~K}-77 \mathrm{KLN}_{2} \text { boilofn }+(77 \mathrm{~K}-20 \mathrm{~K} \text { AMR })\right. \\
\eta=0.40 \quad \eta=0.49\end{array}$ & $\eta=0.25$ & 0.8 \\
\hline $\begin{array}{l}\text { All magnetic } \\
\text { (future) }\end{array}$ & $\begin{array}{c}(300 \mathrm{~K}-77 \mathrm{KAMR})+(77 \mathrm{~K}-20 \mathrm{~K} \mathrm{AMR}) \\
\eta=0.45 \quad \eta=0.49\end{array}$ & $\eta=0.28$ & 0.7 \\
\hline
\end{tabular}

*The efficiency of a $5 \mathrm{t} / \mathrm{d} \mathrm{H}$ liquefier is $25 \%$ per Air Products, the $20 \%$ value is our estimate for a $1 \mathrm{v} / \mathrm{d}$ all-gas $\varphi_{2}$ liquefier 


\section{REFERENCES}

1. J.A. Barclay and W. A. Steyert, Cryogenics, 22, 73 (1982). "Materlals for Magnetic Refrigeration Between $2 \mathrm{~K}$ and $20 \mathrm{~K}$.

2. T. Hashimoto, et al., Cryogenics, 21, 647 (1981). "Magnetic Refrigeration in the Temperature Range from $10 \mathrm{~K}$ to Room Temperature."

3. C.B. Zimm, et al., J. Appl. Phys., 55. 2609 (1984). “Low Hysteresis Matertals for Magnetic Refrigeration: Gd $1-\mathbf{x} \operatorname{Er}_{\mathbf{X}} \mathrm{Al}_{2}$."

4. P. Weiss and A. Piccard, C.R. Acad. Sci. (Paris) 166, 352 (1918).

5. H.H. Potter, Proc. R. Soc. (London) 146, 326 (1934).

6. S.M. Benford and G.V. Brown, J. Appl. Phys., 52, 2210 (1981). "T-S Diagram for Gadolinlum Near the Curie Temperature."

7. L. Brillouin and H.P. Iskenderian, Elec. Comm., 25, 300 (1948). "Thermomagnetic Generator."

8. J.F. Elliot, J. Appl. Phys., 30. 1774 (1959). "Thermomagnetic Generator."

9. L.D. Kirol and J.L. Mills, J. Appl. Phys., 56, 3 (1984). "Numerical Analysis of Thermomagnetic Generators."

10. D. Solomon, J. Appl. Phys., 65, 3687 (1989). “Thermomagnttic Mechanical Heat Engines."

11. S. Pappell, NASA Lewis Research Center (1965). U.S. Patent 3,215,572.

12. E.L. Resler and R.E. Rosenweig. J. Eng. Power, p. 399 (1967). "Regenerative Thermomagnetic Power."

13. E. Van Der Voort. Appl. Scl. Res., 20, 98 (1969). "Ideal Magnetocaloric Conversion."

14. J. Poppelwell and S. Charles, in Proceedings of Ferrofluid Conference entitled Thermomechanics of Magnetic Fluids, edited by B. Berkowsky (Hemisphere Publishing Co., Washington, DC, 1978).

15. G.V. Brown, IEEE Trans. on Mag., MAG-13, 1146 (1977). "Magnetic Stirling Cycles - A New Application for Magnetic Materlals."

16. G.V. Brown. J. Appl. Phys., 47, 3673 (1976). “Magnetic Heat Pumping Near Room Temperature."

17. P. Debye, Ann. Phys., 81, 1154 (1926). “Einize Burnerkungen zur Magnetisierung bei tiefer Temperature."

18. W.F. Giauque, J. Am. Chem. Soc., 49, 1870 (1927) and W.F. Giauque and I.D.P. MacDougall, Physical Review, 43, 768 (1932). "Attainment of Temperatures Below $1 \mathrm{~K}$ Absolute by Demagnetization of $\left.\mathrm{Gd}_{2}\left(\mathrm{SO}_{4}\right)_{3} \cdot 8 \mathrm{H}_{2} \mathrm{O}\right)$."

19. J.R. van Geuns, Phillps Research Report Suppl. 6. (1966!. "A Study of a New Magnetic Refrigerating Cycle." 


\section{REFERENCES}

(Continued)

20. J.A. Barclay, Adv. in Cryog. Eng., 33. 719 (1988). "Magnetic Refrigeration: A Review of a Developing Technology" and references therein.

21. A.F. Lacaze, Proc. Int'l Inst. of Refrigeration Conf., Prague, 1986, p. 99-110, "Magnelic Refrigeration - An Overvlew."

22. T. Hashimoto, Adv. in Cryog. Eng. . 32, 261 (1986). "Recent Investigations on Refrigerants for Magnetic Refrigerators."

23. L. D. Kimol and M.W. Dacus, Adv. in Cryog. Eng., 33 757 (1988). "Rotary Recuperative Magnetic Heat Pump."

24. G. Patton, G. Green, J. Sevens, and J. Humphrey, Proc. 4th Int'l Cryocooler Conf., Easton, MD, Sept. 25-26 (1986), "Reclprocating Magnetic Refrigerator."

25. J.A. Barclay and W.A. Steyert, Electric Power Research Institute (EPRI) Final Report EL-1757, Aprll, 1981. "Magnetic Refrigerator Development."

26. G.V. Brown, Am. Soc. of Heating. Refrigeration, and Air Conditioning Engineers Trans., 87. 783-793 (1981). “Basic Principles and Possible Configurations of Magnetic Heat Pumps."

27. J.R. Hull and K.L. Uherka, Proc. 23rd Intersciclety Energy Conv. Engng. Conf., Denver. -U, P. 531-536; July 31-Aug. 5 (1988): "Magnetic Heat Pumps."

28. "Prrredings of the Magnetic Heat Pump Workshop," (P.E. Scheihing, editor), Oct. 27. 1988, Herndon, VA; U.S. Dept. of Energy, Office of Industrial Programs.

29. The Market Potential for Electrolytic Hydrogen, Report prepared by the Futures Group. Glastonbury, CT, for the Electric Power Research Institute. EPRI Project No. 1086-4. Report No. EM-1 154, Palo Alto, CA, August 1979.

30. Lee Gaumer, Alr Products and Chemicals, lnc.; private communication (1989).

31. C.R Baker and R. Shaner, Int. J. Hydrogen Energy. 3.321 (1978). "A Study of the Efficiency of Hydrogen Liquefaction."

32. R. Barron, Cryogentc Systems. Oxford Unjversity Press (1985).

33. Cryogenic Engineering, edited by B.A. Hands, Academic Press (1986).

34. C.R. Cross, J.A. Barclay, A.J. DeGregoria, S.R. Jaeger, and J.W. Johnson, Adv. in Cryog. Eng., 33. 767, Plenum Press, New York (1988). "Optımal Temperature Entropy Curves for Magnetic Refrigeration."

35. J.A. Waynert, A.J. DeGregorla, S.R. Jaeger, J.W. Johnson, and J.A. Barclay, report prepared by Astronautics Corp. of America for Argonne National Laboratory under DOE-ECUT/EPRI sponsorship (July 1988). "Assessment of the Impact of High Temperature Superconductors on Room Temperature Magnetic Heat Pumps/Refrigerators."

36. S. Whitaker, AICHE J., 18, 2 (1972). "Forced Convection Heat Transfer Correlations for Flow in Pipes, Past Flat Plates, Single Cylinders, Single Spheres, and for Flow in Packed Beds and Tube Bundles." 
37. G.S.G. Beveridge and D.P. Haughey, Int. J. Heat \& Mass Transfer, 14, 1093-1113 (1971). "Axial Heat Transfer in Packed Beds: Stagnant Beds Between 20 and 750 C."

38. S. Sarangi and H.S. Baral, Cryog., 27 (1986). "Effects of Axdal Conduction in the Fluid on Cryogenic Regenerator Derformance."

39. I. F. Macdonald, et al., Ind. Eng. Chem. Fundam., 18, 199-208 (1979). "Flow Through Porous Media - the Ergun Equation Revisited."

40. W.R. Johanson, G. Plerce, C.B. Zimm, and J.A. Barclay, J. Appl. Phys., 64, 5892 (1988).

41. R.D. McCarty, J. Hard, and H.M. Roder, NBS Monograph 168 (1981). "Selected Properties of Hydrogen."

42. N.B. Vayaftik, Hemisphere Publishing (1975). "Tables on the Thermophysical Properties of Liquids and Gases." 